\title{
Article \\ A wavelet multiscale mathematical model for quality of life index measuring
}

\author{
Majed S. Balalaa ${ }^{1,+}$ and Anouar Ben Mabrouk $2,3,4,+(\mathbb{D}$ \\ 1 Deanship of Public Relations and Media, University of Tabuk, 47512 Tabuk, Saudi Arabia; Email: \\ mbalalaa@ut.edu.sa (M.S.B.) \\ 2 Laboratory of Algebra, Number Theory and Nonlinear Analysis, Department of Mathematics, Faculty of \\ Sciences, University of Monastir, Avenue of the Environment, Monastir 5019, Tunisia; \\ 3 Department of Mathematics, Faculty of Sciences, University of Tabuk, Tabuk 47512, Saudi Arabia \\ 4 Department of Mathematics, Higher Institute of Applied Mathematics and Computer Science, University \\ of Kairouan, Street of Assad Ibn Alfourat, Kairouan 3100, Tunisia; Anouar.benmabrouk@fsm.rnu.tn \\ (A.B.M.) \\ * Correspondence: anouar.benmabrouk@fsm.rnu.tn \\ + These authors contributed equally to this work.
}

\begin{abstract}
The present paper is concerned with the study of the quality of life index. Such an index has become an important index for measuring the well-being of individuals. However, the quality of life index is always a subjective, intangible, and often hard to quantify with precision due to the lack of quantitative models dealing with. The main goal of the present paper is thus to propose a mathematical, quantitative model for the measurement of a quality of life index. The main novelty is firstly the construction of a wavelet dynamic multiscale model to quantify and investigate the effect of time scale on the quality of life index measuring. The proposed procedure is acted empirically on a sample corresponding to Saudi Arabia as a case of study during the period from 2003 to 2020 as part of the 2030-vision plan. Saudi Arabia has implemented the so-called 2030-vision plan where the quality of life improvement is one of the main goals to be attempted. The findings show that wavelets are capable to localize the time-wise behavior of the index contrarily to classical studies which estimate a global view of the index. Moreover, the study shows the link between the quality of life behavior and many other indices.
\end{abstract}

Keywords: Wavelets; Quality of life, Mathematical models.

MSC: 62B10, 62B15, 65T60.

JEL Classification: C02, C6, C63, I1, I3, I31, I38.

\section{Contents}

$\begin{array}{ll}\text { Introduction } & 2\end{array}$

Quality of life brief overview 3

Different measurements of the quality of life . . . . . . . . . . . . . . 3

Quality of life and Marketing . . . . . . . . . . . . . . . . . . 4

TRe impact on the whole community . . . . . . . . . . . . 4

Recent Quality of life mathematical model review $\quad 4$

Development of a multiscale wavelet model $\mathbf{5}$

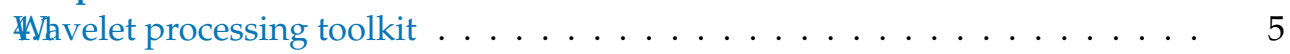

Wavelet adjustment of data samples . . . . . . . . . . . . . . 7

The multiscale mathematical model . . . . . . . . . . . . . . 9 


\section{Introduction}

Quality of life is nowadays a major and important concept in the evaluation of the modern life well-being. The major drawback in such an index is due to its subjectivity and intangibility compared to the standard of living concepts and factors. It is till now hard to measure such an index in a complete way that may be applied in all situations, such as healthy well-being, economically well-being, ... etc. This is due to the fact that this index is often hard to quantify as the factors that may be involved and that affect the overall quality of life vary by people's lifestyles and their personal preferences.

In the last years, the Kingdom of Saudi Arabia represented by its Council of Economic Affairs and Development has implemented the so-called 2030-vision, a block of programs and plans of strategic importance for the government of Saudi Arabia.

One of the strategic objectives to be established in such a vision is the programs of the Quality of Life which aims essentially to make the kingdom one of the most suitable destination for both its citizens, and also for foreigners and residents as a top living place, and thus a top and/or high quality of life index.

Regardless of these factors, this measure plays an essential part in the financial decisions in everyone's lives. The purpose of this paper is to understand the topics or the factors and/or indices that seeks to improve the quality of life.

In the present project, we aim essentially to study the quality of life and its measurements in view of KSA 2030-vision and policy to conclude about the effects of life quality on the economic situation in KSA, and the general situation forecasting in Saudi Arabia as best destination as implemented and aimed in the 2030-vision plans and the possibility to reach such goal in view of quantitative indices.

Our basic idea reposes on the application of wavelet theory as a new mathematical tool non widely applied in social sciences. The application of wavelet analysis on the data results in a decomposition into many components. A first component reflects the global shape of the data, and other components containing the noise, and describe more adequately the fluctuations hidden in the data according to different horizons known as levels of decomposition or also time scales. Wavelets indeed, posses some special mathematical requirements useful in data representation. For example, for non-stationary data, wavelets are efficient descriptors for trend, volatility clustering and variance due to their ability to take into account both frequency and time in the multi-resolution.

Due to many reasons, such as the availability of data in both web sites designated for it, or the social media texts which are in the heart of our study to estimate and show their influence on the different situations of the countries, economic, political, or also social, and in order to possibly compare with existing ideas in measuring quality of life index, we proposed a mathematical multi-scale in time wavelet model based on the following factors or variables to be estimated. The first variable is due to the Gross Domestic Product (GDP, in Millions of Saudi Riyals), the second is the Gross National Income (percentage of GDP), the third is estimated by the Gross Savings (percentage of GDP). The model will include also the Unemployment rate, the Energy Consumption per Capita, the Death Rate, the life expectancy and the Education index (as percentage of GDP).

The main difference with the last existing model due to [7] is the involvement of a time scale procedure which permits to detect the time-wise or the time scale behavior of the quality of life index as well as other variables, instead of the one global index computed in [7]. The new procedure will show clearly the movement of the market and 
generally the situation of the country, and to also forecast its ability to be really a suitable future destination as a top living city.

Finally, the sample of data to be applied will be based on annual values of the variables raised above traded on the period 200 to 2021. This is a remarkable period characterized by many political, economic and financial movements such as Qatar embargo, Yemen war, NEOM project, 2030 KSA vision, the Arab spring, and lastly the COVID-19 pandemic. All these factors have surely strong affects and thus make the findings in the present work to be good bases for understanding current and future situations and may be thus bases of future decisions.

Recall that the estimated indices especially in social sciences are very little taking into account the time scale, and are estimated instead relatively to the entire periods of the study. This means in time scale speaking that the indices are assumed to be stable relatively to a certain scale. While in reality the variance with the society such as the market, money, investments, brand sales and equity varies over time and therefore there should be some statistical issues to be considered related to errors in the estimates of individual well-being, securities, and their instabilities.

The present paper will follow the following plan. Section 2 is concerned with an overview on the quality of life and the related concepts. Section 3 will review briefly the last known models that proposed a quantitative measure for the quality of life. In section 4, we will develop our idea for a quantitative mathematical model to measure a quality of life index. In a first step, an adjustment of the data based on wavelets will be provided. Next,a multi-scale wavelet model will be developed involving the time scale and wavelet decomposition into the model. Section 5 is devoted to the empirical results and their discussion. Section 6 is a final conclusion.

\section{Quality of life brief overview}

\subsection{Different measurements of the quality of life}

To understand and/or to conclude whether a person or society has reached some level of life quality, several measurements have been defined by researchers. Some of them are subjective, others are qualitative. However few if not no one are quantitative. Some researchers considered personal well-being aspects such as emotional experience, joy, stress, sadness, anger, and affection as factors to measure the quality of life. Others suggest to measure or to compare to some scale or threshold to conclude I the person is living well. The scale may be related to income, to fertility, to productivity, to the education level. Health care, wealth and materialistic goods are also factors that are taken into consideration in many cases. In developing countries for example and/or poor countries we know that health care and social securities are not well supported by the states.

However, in these countries and poor societies a great part of the community relates the quality of life to other even simple actors such as global family happiness, living in family, especially in a safe situation. We know that in many countries such as India, south African countries, south America and even in USA the overage of crime is high. This makes the life unsafe.

Besides, sociologists considered the so-called physical quality of life index based on basic literacy, infant mortality, and life expectancy and sometimes country's ecological footprint as an indicator.

In political economics to measure the quality of life, researchers considered liveability which takes into account the place of birth, the place of childhood, family situation and stability such as the rate of divorce in the society, satisfaction of the infrastructure. Other factors may be also included such as government taxation, government aid, sponsorship programs, freedom and political rights, the rate of employment and racism. 


\subsection{Quality of life and Marketing}

One of the important concepts that may be related or regarded simultaneously with quality of life is marketing. Although most relevant links between marketing and quality of life appear in theory only in the last two decades.

Nowadays governments, organizations and individuals are paying more interest to how their activities impact on quality of life at the regional, national and global levels. Factors such as global resources, environmental circumstances, politics, competition, technology, education may have a significant impact on populations regardless of their level of development.

A conceptualization of quality of life based on the involvement of citizens in exchanging resources to new resources or to ultimate satisfaction in a set of arenas of action may be of interest. The so-called objective and subjective approaches to measuring quality of life address different aspects of the exchange relationships and their context.

Marketing at least indirectly may contribute to a higher quality of life by rendering work life possible and by providing the goods and services entering the consuming life arena. Besides, marketing may induce a negative influence by giving priority to short-term, materialistic needs.

Moreover, quality of life defined as the individuals' subjective perceptions on objective conditions related to welfare and standard of living may be a main cause of decisions on consumption and purchase, therefore marketing specialists should take it into consideration when developing the product, establishing the price, design the distribution system and the communicational strategy.

Another link may be due to the influence on social marketing, given that this is an area of marketing that is concerned especially with society's problems, trying to promote a responsible behaviour for firms and citizens, in order to increase the level of satisfaction with every aspect of life.

The present project aims to build a research in quality of life and marketing by reviewing the research literature dealing with this concept and develop a set of antecedents and consequences of that relationship. The task of marketing in quality of life may be regarded marketing practices designed to enhance the well-being of customers while preserving the well-being of the firm's other stakeholders. We think that the consequences of marketing beneficence and normal efficiency are high levels of customer well-being, customer trust and commitment, and positive corporate image and company goodwill. These factors may also be influenced by environmental factors, organizational factors, and individual factors.

\subsection{The impact on the whole community}

Understanding and providing quantitative and qualitative measurements of life quality in the country will help individuals, investors as well as companies to decide that it is a best target place to be installed for their future projects. This will improve the society also from many points of view:

- Investments will participate in decreasing the rate of unemployment.

- Investments permit to the country be transferred to an industrial country that will export technology, foods, drags, energy more than importing.

- High-level educated individuals will improve the scientific level such as research in national universities. This will improve the rank of these universities and will give them an international aspect. There will be possible to interchange students and researchers worldwide.

- These facts will have a positive effect on the growth, the development and thus the economic situation in the country.

\section{Recent Quality of life mathematical model review}

In the literature review on quality of life mathematical models, unfortunately there are few ideas that apply really exact mathematical models to provide an exact powerful 
measure for such an index. This is due to the fact that quality of life may be viewed in different views according to the field of examination. Health quality is different from economic quality. This later is in turn different from social well-being. Political situation, human rights are also factors that may be included in the evaluation of the satisfaction of people against the citizenship.

One of the recent models that seems to be a step ahead perhaps (in our knowledge) is due to [7] where the author has introduced a mathematical model to estimate some real-valued measurement of the QoL. The model in its original form is based majorly on economic variables issued from knowledge and introduced in [7]. It applies the following variables,

- $x_{1}^{t}$ health,

- $x_{2}^{t}$ family life,

- $x_{3}^{t}$ community life,

- $x_{4}^{t}$ financial situation (GDP per capita, in \$),

- $x_{5}^{t}$ political stability and security,

- $x_{6}^{t}$ climate and geography,

- $x_{7}^{t}$ job safety (unemployment rate),

- $x_{8}^{t}$ political freedom,

- $x_{9}^{t}$ gender equality,

- $L E$ life expectancy at birth,

- LEI life expectancy index,

- EI degree of access to education,

- MYSI education period,

- $\quad$ II revenue indicator,

- $\quad$ GNIpc gross national income at purchasing power parity per capita.

As explained in [7], the variables $x_{1}^{t}, \ldots, x_{9}^{t}$ are assumed to be independent, and reflect the mathematical the objective characteristics of the quality of life, giving individuals in a society the subjective satisfaction at a given time $t$. Denote for the next $\bar{X}$ the arithmetic mean of the $x_{1}^{t}, \ldots, x_{9}^{t}$. The mathematical model provides an index HDI relative to a period of time $\left[t_{0}, t_{1}\right]$, as an overage

$$
H D I_{m}=\frac{1}{\left(t_{1}-t_{0}\right)^{2}} \int_{t_{0}}^{t_{1}} H D I(t) d t . \int_{t_{0}}^{t_{1}} \bar{X}(t) d t,
$$

where at an instant of time $t$, we have

$$
\begin{gathered}
H D I=\sqrt[3]{L E I \times E I \times I I} \\
L E I=\frac{L E-20}{82.3-2.0}, E I=\frac{\sqrt{M Y S I \times E Y S I}}{0.951} \\
M Y S I=\frac{M Y S}{13.2}, E Y S I=\frac{E Y S}{20.6} \\
\frac{\ln (G N I p c)-\ln 100}{\ln (107.721)-\ln 100}
\end{gathered}
$$

\section{Development of a multiscale wavelet model}

In the present section, we provide details concerning the mathematical model to be investigated in the present paper. In fact, such a model is not completely new, but the new task resides in the involvement of the time scale parameter, and the use of wavelets in the construction or the adjustment of the data sample to be applied.

\subsection{Wavelet processing toolkit}

Wavelets have been introduced few decades ago in mathematical theory, although their discovery was related to applications in petroleum extraction $([2,3,16,19,22]$ 
A wavelet is simply a short wave function oscillating like the cosine and sine, but with high frequency and small support, which we call in wavelet theory localization in time-frequency, and/or time-space.

To analyse a statistical (time, financial, ...) series we have to compute the so-called wavelet transform, a 2-parameters quantity valuated by a correlation-type (a convolution) of the analyzed series with translated-dilated copies of one fixed wavelet known as the mother wavelet, a special function that should satisfy at least an admissibility assumption as

$$
\mathcal{A}_{\psi}=\int_{\mathbb{R}} \frac{|\widehat{\psi}(\xi)|^{2}}{|\xi|} d \xi<\infty
$$

These translated-dilated copies are defined by

$$
\psi_{j, k}(t)=2^{j / 2} \psi\left(2^{j} t-k\right) .
$$

The parameter $j \in \mathbb{Z}$ is known as the scale, or also the frequency. The parameter $k \in \mathbb{Z}$ is known as the position or translation. The wavelet transform of a series $X(t)$ (known also as the discrete wavelet transform (DWT)) is obtained by correlation-type (discrete convolution)

$$
d_{j, k}(X)=\sum_{n} X(n) \psi_{j, k}(n)
$$

known also the wavelet coefficient or detail coefficient at the level $j$, and the position $k$. form as

In wavelet theory, it is proved that any series $X(t)$ may be decomposed in a series

$$
X(t)=\sum_{j, k} d_{j, k}(X) \psi_{j, k}(t)
$$

known as the wavelet series or the wavelet decomposition of $X(t)$, and guarantees a complete reconstruction formula of the original series $X(t)$.

The most advantage in this decomposition is the fact that it allows to split the data into different horizons known as levels. Each level is associated to a component of the series, and it makes itself a refinement of the preceding one, which we call in wavelet theory the concept of multi-resolution. Denote for $j \in \mathbb{Z}, W_{j}=\operatorname{spann}\left(\psi_{j, k} ; k \in \mathbb{Z}\right)$ (known as the detail space at the level js), and $V_{j}=\bigoplus_{l \leq j}^{\perp} W_{l}$ (known as the approximation space at the level $j$ s). We get an orthogonal decomposition $V_{j}=V_{j-1} \stackrel{\perp}{\bigoplus} W_{j-1}$. This permits to split the wavelet decomposition above as

$$
X(t)=\sum_{j \leq J_{\min }, k} d_{j, k}(X) \psi_{j, k}(t)+\sum_{j>J \min , k} d_{j, k}(X) \psi_{j, k}(t),
$$

relative to a fixed integer $J_{\min } \in \mathbb{Z}$. For $j \in \mathbb{Z}$, the component

$$
A_{j}(X(t))=\sum_{l \leq J, k} d_{l, k}(X) \psi_{l, k}(t)
$$

belongs to $V_{j}$, and is called the approximation of $X(t)$ at the level $j$. It describes the global behavior, the trend, or the shape of $X(t)$. The component

$$
D_{j}(X(t))=\sum_{k} d_{j, k}(X) \psi_{j, k}(t)
$$

belongs to the space $W_{j}$, and is called the detail component of $X(t)$ at the level $j$. It reflects the higher frequency oscillations or the fine scale deviations of the series near its trend. As a consequence, the wavelet decomposition of $X(t)(6)$ is a superposition as

$$
X(t)=A_{J_{\min }}(X(t))+D_{J_{\min }+1}(X(t))+D_{J_{\min }+2}(X(t))+\ldots
$$


A second main advantage of wavelet theory is the reduction in computing the coefficients needed in the decomposition. Indeed, there exists a function $\varphi$ (known as the scaling function or the father wavelet) characterized by the so-called 2-scale relation

$$
\varphi=\sum_{k \in \mathbb{Z}} h_{k} \varphi_{1, k}
$$

and which is related to the function $\psi$ by

$$
\psi=\sum_{k \in \mathbb{Z}} g_{k} \varphi_{1, k}
$$

where

$$
h_{k}=\int_{-\infty}^{+\infty} \varphi(t) \varphi_{1, k}(t) d t, \text { and } g_{k}=(-1)^{k} h_{1-k} .
$$

It holds that $V_{j}=\operatorname{spann}\left(\varphi_{j, k} ; k \in \mathbb{Z}\right)$, where the $\varphi_{j, k}$ 's are defined similarly to the $\psi_{j, k}$. The component $A_{J}(X(t))$ is therefore written as

$$
A_{J}(X(t))=\sum_{k} a_{J, k}(X) \varphi_{J, k}(t)
$$

where the coefficients $a_{j, k}(X)$ (known as the approximation or scaling coefficients of $X(t))$ are evaluated as the $d_{j, k}(X)$ by replacing the function $\psi$ by $\varphi$. The relation (10) permits to compute the level decomposition from each other as

$$
a_{j, k}(X)=\sum_{l \in \mathbb{Z}} h_{l} a_{j+1, l+2 k}(X),
$$

and

$$
d_{j, k}(X)=\sum_{l \in \mathbb{Z}} g_{l} a_{j+1, l+2 k}(X)
$$

and

$$
a_{j+1, k}(X)=\sum_{l} h_{l-2 k} a_{j, l}(X)+\sum_{l} g_{l-2 k} d_{j, l}(X) .
$$

The sequence $H=\left(h_{k}\right)_{k}$ is called the discrete wavelet low-pass filter, the sequence $G=\left(g_{k}\right)_{k}$ is the discrete wavelet high-pass filter.

The truncation of the last decomposition in (9) in a practical finite level $J>J_{\min } \in \mathbb{Z}$ gives the so-called $J$-level finite wavelet decomposition of $X(t)$ as

$$
S_{J}=A_{J_{0}}(S)+\sum_{J_{0}<j \leq J} D_{j}(S) .
$$

The lower index $J_{\min }$ is in fact more flexible, and usually chosen to be 0 . The choice of $J$ is always critical, and is related to the eventual error estimates requested. See $[2,3,16,19,22]$ for more details.

\subsection{Wavelet adjustment of data samples}

A major problems in data processing or data analysis that is always confronted by researchers and analysts is related to its availability and veracity. These are known in data analysis as missing, fuzzy, uncertain, and also fake data.

To overcome these problems, many tools have been developed by researchers to adjust the data, and thus to build complete samples to be used adequately.

In our present situation, this problem is present strongly, as our data are in the majority collected from media such as web sites, social media sites, ..., etc. Even in many governmental sites, the authorities did not provide for many times a complete data. This is of course and generally related to many causes when the data for examples touches 
the policy and/or the secrets of the countries, and also when the data may yield unstable movements.

In our case, to build a complete sample, and thus to re-construct the missing and the uncertain parts, we applied wavelet method able reconstruct our short time series on an arbitrarily set of backwards and/or forwards (past and/or future, prior and/or post) values. Recall that to obtain good re-constructions in the case of statistical series, it is needed to have a long-time past interval for training. This fact may not be satisfied in general situations such as the present one. Besides, all the existing procedures considered only the re-construction of future values by means of preceding ones, i.e., just a forecasting procedure. See for example [5], [34], [35] and the references therein.

In our case, some values that are missing are unfortunately at the beginning of the period. We re-applied a modified version of the method developed in $[5,28]$. Our new idea consists first in applying a backward-forward method to reconstruct missing data. The method is principally characterized by the non-necessity to test it on the detail parts components of the series nor its wavelet coefficients. This is essentially due to the fact that we use few values of series leading to short sub-samples and next act the prediction on the sub-samples. The most positive point in the method is the fact that it necessitates only to compute the values of the source scaling function and the associated wavelet on a suitable grid, the dyadic or the integer grid in the supports of the mother and father wavelets. Such values are well estimated in [16], which motivated the application of Daubechies wavelets in the empirical part.

We will recall her-after this procedure. Let $\left(t_{i}, X_{i}\right), i=1,2, \ldots, N$ be the statistical series, and its wavelet decomposition at a level $J$,

$$
X^{J}=\sum_{k} a_{0, k} \varphi_{0, k}+\sum_{j=1}^{J} \sum_{k} d_{j, k} \psi_{j, k}
$$

The missing values will be categorized into two classes.

- A missing value $X_{k}$, is situated between two segments of known values, after and before it. We thus chose the one with greater length for the prediction of the missing value $S_{k}$. Denote, for example, $L_{k}$ the length of the greater segment $I_{k}=\left\{i_{1}^{k}, i_{2}^{k}, \ldots, i_{L_{k}}^{k}\right\}$.

- Consider next the truncated time series $\widetilde{X}_{i}$ corresponding to $\left(t_{i}, X_{i}\right), i \in I_{k}$, and its wavelet decomposition as in (18).

- If $I_{k}$ is an after-interval to $X_{k}$, we estimate the value $X_{i_{1}^{k}-1}$ by

$$
X_{i_{1}^{k}-1}=\sum_{l} a_{0, l} \varphi\left(i_{1}^{k}\right)+\sum_{j=1}^{J} \sum_{l} d_{j, l} \psi\left(2^{j}\left(i_{1}^{k}\right)-l\right)
$$

- If $I_{k}$ is a before-interval to the missing value, we estimate the value $X_{i_{L_{k}}^{k}+1}$ by

$$
X_{i_{L_{k}}^{k}+1}=\sum_{l} a_{0, l} \varphi\left(i_{L_{k}}^{k}+1-l\right)+\sum_{j=1}^{J} \sum_{l} d_{j, l} \psi\left(2^{j}\left(i_{L_{k}}^{k}+1\right)-l\right) .
$$

- Whenever the after and before intervals have the same length we take the mean value of the two predicted ones.

- In the case where many successive values are missing, we take the extremities of the missing segments as starting points to be re-constructed.

- Finally, each predicted value is added to the series, and the new series is reconsidered for the next step.

We recall again that the process necessitates to know the values of $\psi$ on the dyadic grid $\left\{2^{j}(N+1)-l, l\right\}$ and those of $\varphi$ on the integer grid $\{N+1-l, l\}$ in the supports. 


\subsection{The multiscale mathematical model}

One of the main variables applied in worldwide regions when estimating many indexes such as the QoL, the poverty rate is one important variable. However, in many cases, such a variable is not provided, despite its existence in the real daily life in the society subject of study. In Saudi Arabia, for example, and which is the case study in our present paper, the index of poverty or the rate is nowhere provided, except some discussions in many global and general reports which are not provided by the concerned authorities. This makes the evaluation of many models such as the one reviewed previously, and which has been mainly simulated in Romania may not yield real description in other cases. This leads us to modify the existing model,by including other indexes or variables, and which may involve even implicitly the lost variables from the existing models such as the poverty in our case. Indeed, our model to be developed involves the Education Index instead, which is strongly related in fact to poverty. We know that one of the main goals in the worldwide authorities, especially UNESCO is to enable all the human kinds especially poor ones to be educated at least to some level.

Otherwise, notice that in the model (1), we get a global index relative to a whole period, which may not reflect the real situation during localized times, as it did not take into consideration the time scale. To improve the model, and exploit the time scale role and influence, we proposed to act a multi-scale QoL index by considering multi-periods time. We estimate a relative HDI according to a time scale $j \in \mathbb{N}$, for which

- the scale 0 corresponds to a period of 1 year dynamics,

- the scale 1 corresponds to a period of 2 years dynamics,

- the scale 2 corresponds to a period of 4 years dynamics,

- the scale $j \geq 0$ corresponds to a period of $2^{j}=2^{j+1}-2^{j}$ years dynamics,

The maximal value of the scale $j$ will be $J_{\max }$ depending on the size of the data sample, or equivalently to the period of the empirical study.

The idea consists in computing for each scale $j$ a corresponding HDI index which will be called as the $j$-level HDI index as follows

$$
H D I_{j}=\frac{1}{2^{2 j}} \int_{2^{j}}^{2^{j+1}} H D I(t) d t . \int_{2^{j}}^{2^{j+1}} \bar{X}(t) d t .
$$

\section{Results and discussion}

In the present section, we aim to apply the multiscale mathematical model developed above to discuss the situation of the QoL measure in Saudi Arabia, based on special data extracted from the social media, which reflects somehow the opinion of both nationals, non-national residents, as well other interested peoples to such a region such as investors from the economic and energy, sectors for example. We essentially focused on the period 2004-2021 resulting in $16\left(2^{4}\right)$ years. As a consequence, the maximum level will be fixed to $j_{\max }=4$.

Our model evaluation will be based on the following variables

- $\quad V_{1}$ : Gross Domestic Product (GDP, in Millions of Saudi Riyals SARs),

- $\quad V_{2}$ : Gross National Income (percentage of GDP),

- $V_{3}$ : Gross Savings (percentage of GDP),

- $V_{4}$ : Unemployment rate,

- $V_{5}$ : Energy Consumption per Capita,

- $V_{6}$ : Death Rate,

- $V_{7}$ : Education index (as percentage of GDP),

- $V_{8}$ : Life Expectancy.

In Table 1 below we provide the values of the variables as gathered. Some of them are compared to existing values already provided in authorised web sites specialised in such data statistics. The valued in red are the missing ones estimated by means of our preceding procedure developed in the previous section. 


\begin{tabular}{c|c|c|c|c|c|c|c|c} 
Year & $V_{1}$ & $V_{2}$ & $V_{3}$ & $V_{4}$ & $V_{5}$ & $V_{6}$ & $V_{7}$ & $V_{8}$ \\
\hline 2003 & 809279 & 11.242 & 34.816 & 5.56 & 6.456 & 3.59 & 0.580 & 73.01 \\
2004 & 970283 & 7.958 & 42.139 & 5.82 & 6.398 & 3.57 & 0.594 & 73.10 \\
2005 & 1230771 & 5.574 & 48.653 & 6.05 & 6.801 & 3.56 & 0.604 & 73.19 \\
2006 & 1411491 & 2.788 & 48.505 & 6.25 & 6.995 & 3.54 & 0.619 & 73.28 \\
2007 & 1558827 & 1.847 & 48.927 & 5.73 & 7.022 & 3.53 & 0.634 & 73.37 \\
2008 & 1949238 & 6.250 & 52.752 & 5.08 & 7.270 & 3.51 & 0.649 & 73.46 \\
2009 & 1609117 & -2.060 & 36.598 & 5.38 & 7.506 & 3.49 & 0.664 & 73.64 \\
2010 & 1980777 & 5.040 & 43.563 & 5.55 & 7.962 & 3.46 & 0.691 & 73.83 \\
2011 & 2517146 & 9.997 & 50.590 & 5.77 & 8.004 & 3.44 & 0.719 & 74.01 \\
2012 & 2759906 & 5.411 & 48.928 & 5.52 & 8.534 & 3.42 & 0.747 & 74.20 \\
2013 & 2799927 & 2.699 & 44.608 & 5.57 & 8.871 & 3.41 & 0.770 & 74.38 \\
2014 & 2836314 & 3.652 & 38.924 & 5.72 & 9.267 & 3.41 & 0.787 & 74.48 \\
2015 & 2453512 & 4.106 & 25.502 & 5.59 & 9.485 & 3.41 & 0.802 & 74.59 \\
2016 & 2418509 & 1.670 & 27.235 & 5.65 & 9.333 & 3.43 & 0.803 & 74.69 \\
2017 & 2582198 & -0.741 & 30.371 & 5.89 & 9.151 & 3.45 & 0.784 & 74.80 \\
2018 & 3062170 & 2.434 & 33.227 & 6.04 & 8.954 & 3.47 & 0.789 & 74.90 \\
2019 & 3013561 & 0.331 & 33.597 & 6.13 & 8.434 & 3.51 & 0.789 & 75.06 \\
2020 & 2637629 & -4.106 & 25.255 & 8.22 & 8.263 & 3.5 & 0.854 & 75.22 \\
\hline
\end{tabular}

Table 1: Caption

Figure 1 illustrates graphically these variables.

Now, we provide the wavelet multi-scale analysis of each variable at the level 4, using herewith the well-known Daubechies wavelet DB8 (See [16]). Tables 2, 3, 4, 5, $6,7,8$ and 9 represents the 4 components due to the 4-level wavelet decomposition. The 1st column in each table represents the approximation component $A_{4}$ relative to each variable, and the $2 \mathrm{nd}, 3 \mathrm{rd}$, 4 th and 5 th columns represent respectively the detail components $D_{1}, D_{2}, D_{3}$, and $D_{4}$ already for each variable.

Next, for further understanding the behavior of these variables according to the time scale, we plotted hereafter the graphs of their trends represented by the four levels of wavelet approximations $A_{j}$, for $j=1,2,3,4$. See Figure 2, Figure 3 , Figure 4 and Figure 5 .

These figures (Figure 2, Figure 3, Figure 4 and Figure 5) reflect the trend or the general shape, and the general behavior of the variables $V_{i}, 1 \leq i \leq 8$. It is clearly noticed the well fitting between each variable (see Figure 1 and its approximation in the different levels, which is always and already confirmed in wavelet theory.

Now, to investigate in more details the impact of the time scale on the quality of life index measurement, we plotted the components due to the wavelet analysis at the maximum level $J=4$ for each variable separately, already numerically provided in Tables 2, 3, 4, 5, 6, 7, 8 and 9 to explore the time scale behavior of these variables or factors. Figures 6, 7, 8 and 9 illustrate the respective wavelet decomposition at the maximum level $J=4$ for the components of the variables $V-i, i=1, \ldots, 8$.

Besides, to be more clear, and to provide readers with detailed illustrations of the variables $V_{i}$ according to time scale, we plotted in Figures 10, 11, 12, 13, 14, 15, 16, 17 the wavelet decomposition of all the variables $V_{i}, 1 \leq i \leq 8$ at the maximum level $J=4$ separately. Notice effectively in these figures the well fitting with the approximation $A_{4}$ (The right-hand sub-figures at the top of Figures 10, 11, 12, 13, 14, 15, 16, 17)

Let us comment on these figures. Figure 10 illustrates the behavior of the variable $V_{1}$ which represents the Gross Domestic Product. Notice that such a variable represents a global shape showing an increase in time. However, its global shape does not reflect the real, and hidden behavior of the variable according to time scale. Indeed, at low scales, $j=1$, the component $D_{1}$ shows quietly the same global behavior, an increasing variation according to time. However, by increasing the level or the scale, the real hidden 


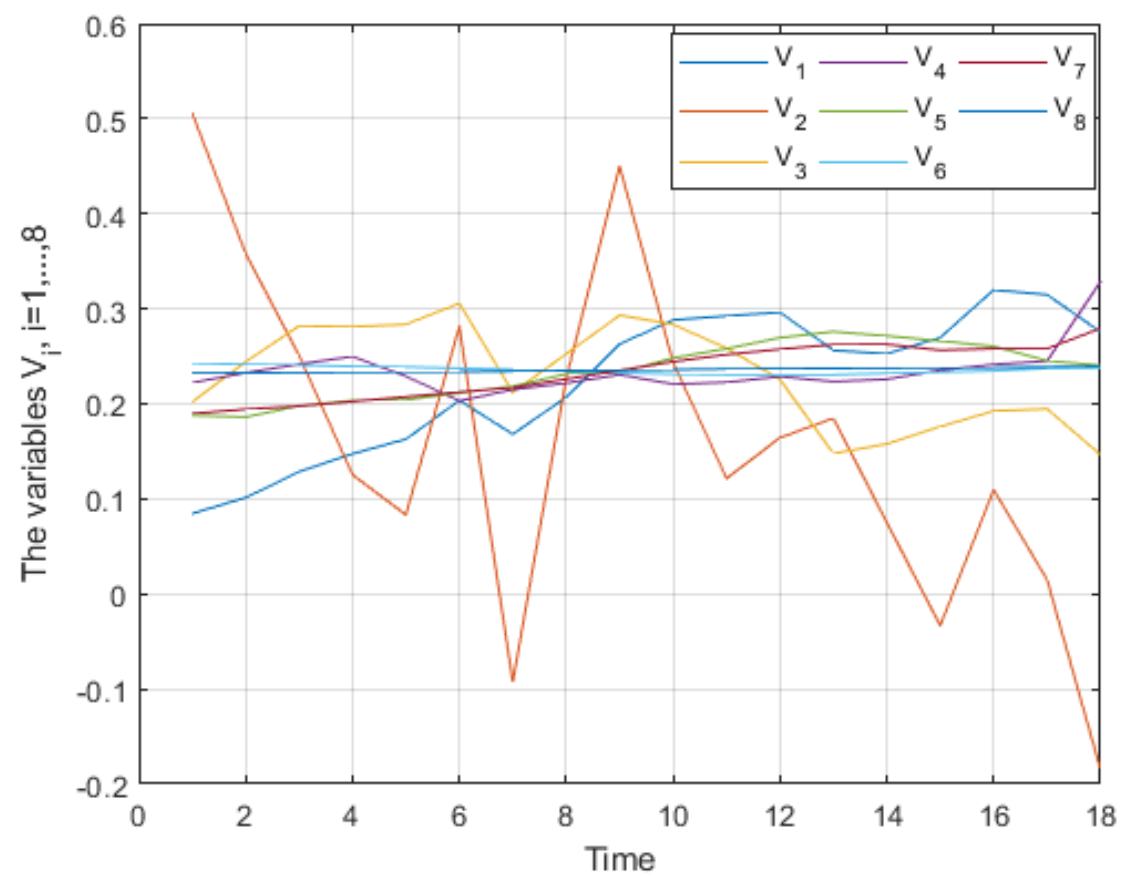

Figure 1. The graph of the eight variables $V_{i}, 1 \leq i \leq 8$.

\begin{tabular}{c|c|c|c|c}
$A_{4}$ & $D_{1}$ & $D_{2}$ & $D_{3}$ & $D_{4}$ \\
\hline 13.6398 & -0.0359 & -0.1138 & -0.0672 & -0.3505 \\
13.7696 & 0.0158 & -0.0194 & -0.1024 & -0.2980 \\
13.9706 & 0.0526 & 0.0865 & -0.1073 & -0.2245 \\
14.1841 & -0.0240 & 0.1539 & -0.0883 & -0.1321 \\
14.3258 & -0.0664 & 0.1181 & -0.0540 & -0.0309 \\
14.3779 & 0.1050 & -0.0025 & -0.0151 & 0.0561 \\
14.3789 & -0.0877 & -0.1416 & 0.0164 & 0.1147 \\
14.4705 & 0.0285 & -0.1568 & 0.0446 & 0.1411 \\
14.6995 & 0.0391 & -0.0022 & 0.0693 & 0.1368 \\
14.8639 & -0.0332 & 0.1117 & 0.0815 & 0.1195 \\
14.8761 & -0.0310 & 0.0862 & 0.0788 & 0.1028 \\
14.8139 & 0.0441 & 0.0099 & 0.0591 & 0.0803 \\
14.7116 & 0.0015 & -0.0846 & 0.0244 & 0.0535 \\
14.6949 & 0.0037 & -0.0927 & -0.0091 & 0.0292 \\
14.8253 & -0.0611 & 0.0372 & -0.0310 & 0.0085 \\
14.9016 & 0.0330 & 0.0993 & -0.0437 & -0.0011 \\
14.8549 & 0.0638 & 0.0241 & -0.0467 & 0.0009 \\
14.8311 & -0.0457 & -0.0238 & -0.0424 & -0.0005 \\
\hline
\end{tabular}

Table 2: 4-level wavelet decomposition of $V_{1}$. 


\begin{tabular}{c|c|c|c|c}
$A_{4}$ & $D_{1}$ & $D_{2}$ & $D_{3}$ & $D_{4}$ \\
\hline 11.0367 & 0.2053 & 2.0380 & 2.3487 & 0.3666 \\
8.6928 & -0.7348 & -0.1612 & 2.3803 & 0.3879 \\
4.7299 & 0.8441 & -2.7730 & 1.2976 & 0.3878 \\
2.4961 & 0.2919 & -2.8414 & -0.5104 & 0.3655 \\
3.4032 & -1.5562 & 0.3882 & -2.4143 & 0.3400 \\
3.3979 & 2.8521 & 1.7395 & -3.3599 & 0.3624 \\
1.8750 & -3.9350 & -0.1305 & -2.6500 & 0.4590 \\
3.3736 & 1.6664 & -0.0957 & -0.8784 & 0.6298 \\
7.3882 & 2.6088 & 2.0807 & 1.2229 & 0.8588 \\
7.8662 & -2.4552 & 1.4130 & 2.6468 & 1.0865 \\
4.0935 & -1.3945 & -1.9316 & 2.5602 & 1.2615 \\
1.9360 & 1.7160 & -2.7348 & 1.5977 & 1.3796 \\
2.7195 & 1.3865 & -0.2637 & 0.3630 & 1.4143 \\
2.7536 & -1.0836 & 1.3615 & -0.6843 & 1.3232 \\
1.6384 & -2.3794 & 1.1667 & -0.9664 & 1.0890 \\
0.3848 & 2.0492 & 0.6175 & -0.9308 & 0.7000 \\
-1.3631 & 1.6941 & -0.3359 & -0.9063 & 0.1747 \\
-2.5174 & -1.5886 & -0.8588 & -0.7252 & -0.4095 \\
\hline
\end{tabular}

Table 3: 4-level wavelet decomposition of $V_{2}$.

\begin{tabular}{c|c|c|c|c}
$A_{4}$ & $D_{1}$ & $D_{2}$ & $D_{3}$ & $D_{4}$ \\
\hline 37.0951 & -2.2791 & -4.7882 & -3.3139 & -0.9225 \\
40.8820 & 1.2570 & -1.2043 & -3.9412 & 0.3596 \\
45.8691 & 2.7839 & 3.0641 & -3.9847 & 1.7042 \\
50.3946 & -1.8896 & 6.2395 & -3.2464 & 3.0227 \\
51.3069 & -2.3799 & 5.3467 & -1.7768 & 4.1736 \\
47.6891 & 5.0629 & 0.1665 & -0.0998 & 4.9549 \\
41.8344 & -5.2364 & -6.5255 & 1.4147 & 5.2298 \\
41.5055 & 2.0575 & -6.8480 & 2.6718 & 4.9631 \\
48.5453 & 2.0447 & 1.2520 & 3.4202 & 4.1864 \\
51.2447 & -2.3167 & 6.1430 & 3.4182 & 3.0632 \\
45.0606 & -0.4526 & 3.1558 & 2.6198 & 1.7588 \\
36.3746 & 2.5494 & -1.4576 & 1.0723 & 0.3260 \\
28.0662 & -2.5642 & -5.3802 & -0.8362 & -1.0869 \\
25.5446 & 1.6904 & -4.4002 & -2.1723 & -2.2382 \\
31.4484 & -1.0774 & 3.3774 & -2.3684 & -2.9759 \\
34.3101 & -1.0831 & 6.6704 & -1.6996 & -3.2190 \\
29.7973 & 3.7997 & 1.5103 & -0.5234 & -2.9828 \\
27.1184 & -1.8634 & -1.9759 & 0.4517 & -2.4919 \\
\hline
\end{tabular}

Table 4: 4-level wavelet decomposition of $V_{3}$. 


\begin{tabular}{c|c|c|c|c}
$A_{4}$ & $D_{1}$ & $D_{2}$ & $D_{3}$ & $D_{4}$ \\
\hline 5.5492 & 0.0108 & -0.3690 & 0.1172 & 0.3401 \\
5.8074 & 0.0126 & -0.0491 & 0.0873 & 0.2660 \\
6.1869 & -0.1369 & 0.4061 & 0.0523 & 0.1718 \\
6.1765 & 0.0735 & 0.4915 & 0.0045 & 0.0595 \\
5.5848 & 0.1452 & 0.0031 & -0.0473 & -0.0655 \\
5.2344 & -0.1544 & -0.2899 & -0.0586 & -0.1921 \\
5.4054 & -0.0254 & -0.1292 & -0.0141 & -0.3117 \\
5.5504 & -0.0004 & -0.0428 & 0.0625 & -0.4191 \\
5.5898 & 0.1802 & -0.0772 & 0.1350 & -0.5100 \\
5.6454 & -0.1254 & -0.0351 & 0.1282 & -0.5845 \\
5.6183 & -0.0483 & 0.0229 & 0.0020 & -0.6401 \\
5.6269 & 0.0931 & 0.1455 & -0.1822 & -0.6659 \\
5.7274 & -0.1374 & 0.3050 & -0.3481 & -0.6519 \\
5.6632 & -0.0132 & 0.1288 & -0.3870 & -0.5890 \\
5.5373 & 0.3527 & -0.3559 & -0.2270 & -0.4706 \\
5.9918 & 0.0482 & -0.4165 & 0.0472 & -0.3021 \\
7.0382 & -0.9082 & 0.0746 & 0.3288 & -0.0918 \\
7.6892 & 0.5308 & 0.2793 & 0.4812 & 0.1488 \\
\hline
\end{tabular}

Table 5: 4-level wavelet decomposition of $V_{4}$.

\begin{tabular}{c|c|c|c|c}
$A_{4}$ & $D_{1}$ & $D_{2}$ & $D_{3}$ & $D_{4}$ \\
\hline 6.3741 & 0.0819 & -0.0981 & 0.1548 & -0.9344 \\
6.5154 & -0.1174 & 0.0106 & 0.0725 & -0.8514 \\
6.7721 & 0.0289 & 0.1355 & 0.0173 & -0.7137 \\
6.9714 & 0.0236 & 0.1405 & -0.0470 & -0.5213 \\
7.0470 & -0.0250 & -0.0114 & -0.1315 & -0.2902 \\
7.2317 & 0.0383 & -0.0849 & -0.1913 & -0.0633 \\
7.5764 & -0.0704 & -0.0120 & -0.2127 & 0.1325 \\
7.8657 & 0.0963 & -0.0106 & -0.1813 & 0.2869 \\
8.0967 & -0.0927 & -0.0913 & -0.0862 & 0.3980 \\
8.4591 & 0.0749 & -0.0577 & 0.0388 & 0.4924 \\
8.9288 & -0.0578 & 0.0790 & 0.1655 & 0.5856 \\
9.2730 & -0.0060 & 0.1262 & 0.2832 & 0.6528 \\
9.4043 & 0.0807 & 0.0523 & 0.3541 & 0.6796 \\
9.3832 & -0.0502 & -0.0135 & 0.3221 & 0.6571 \\
9.2003 & -0.0493 & -0.0451 & 0.1676 & 0.5726 \\
8.8634 & 0.0906 & -0.0825 & -0.0746 & 0.4401 \\
8.4889 & -0.0549 & -0.0892 & -0.3328 & 0.2687 \\
8.2506 & 0.0124 & -0.0177 & -0.4704 & 0.0502 \\
\hline
\end{tabular}

Table 6: 4-level wavelet decomposition of $V_{5}$. 


\begin{tabular}{c|c|c|c|c}
$A_{4}$ & $D_{1}$ & $D_{2}$ & $D_{3}$ & $D_{4}$ \\
\hline 3.5860 & 0.0040 & 0.0065 & -0.0023 & 0.0700 \\
3.5754 & -0.0054 & 0.0013 & 0.0038 & 0.0589 \\
3.5577 & 0.0023 & -0.0063 & 0.0101 & 0.0436 \\
3.5407 & -0.0007 & -0.0086 & 0.0162 & 0.0246 \\
3.5288 & 0.0012 & -0.0017 & 0.0209 & 0.0035 \\
3.5121 & -0.0021 & 0.0039 & 0.0207 & -0.0158 \\
3.4874 & 0.0026 & 0.0038 & 0.0141 & -0.0307 \\
3.4623 & -0.0023 & 0.0031 & 0.0026 & -0.0406 \\
3.4390 & 0.0010 & 0.0017 & -0.0113 & -0.0452 \\
3.4203 & -0.0003 & -0.0006 & -0.0224 & -0.0473 \\
3.4102 & -0.0002 & -0.0016 & -0.0267 & -0.0485 \\
3.4078 & 0.0022 & -0.0031 & -0.0253 & -0.0474 \\
3.4128 & -0.0028 & -0.0049 & -0.0191 & -0.0435 \\
3.4281 & 0.0019 & -0.0027 & -0.0095 & -0.0372 \\
3.4513 & -0.0013 & 0.0032 & 0.0012 & -0.0282 \\
3.4756 & -0.0056 & 0.0071 & 0.0131 & -0.0179 \\
3.4955 & 0.0145 & 0.0061 & 0.0241 & -0.0068 \\
3.5077 & -0.0077 & 0.0012 & 0.0284 & 0.0066 \\
\hline
\end{tabular}

Table 7: 4-level wavelet decomposition of $V_{6}$.

\begin{tabular}{c|c|c|c|c}
$A_{4}$ & $D_{1}$ & $D_{2}$ & $D_{3}$ & $D_{4}$ \\
\hline 0.5827 & -0.0027 & -0.0051 & 0.0128 & -0.0564 \\
0.5908 & 0.0032 & 0.0004 & 0.0064 & -0.0523 \\
0.6045 & -0.0005 & 0.0056 & 0.0004 & -0.0450 \\
0.6199 & -0.0009 & 0.0086 & -0.0068 & -0.0343 \\
0.6336 & 0.0004 & 0.0066 & -0.0144 & -0.0216 \\
0.6481 & 0.0009 & 0.0006 & -0.0174 & -0.0100 \\
0.6658 & -0.0018 & -0.0066 & -0.0138 & -0.0014 \\
0.6895 & 0.0015 & -0.0101 & -0.0049 & 0.0035 \\
0.7196 & -0.0006 & -0.0072 & 0.0071 & 0.0051 \\
0.7472 & -0.0002 & -0.0027 & 0.0154 & 0.0058 \\
0.7682 & 0.0018 & 0.0021 & 0.0155 & 0.0073 \\
0.7888 & -0.0018 & 0.0120 & 0.0105 & 0.0086 \\
0.8050 & -0.0030 & 0.0211 & 0.0031 & 0.0093 \\
0.8002 & 0.0028 & 0.0092 & -0.0032 & 0.0098 \\
0.7798 & 0.0042 & -0.0209 & -0.0048 & 0.0097 \\
0.7826 & 0.0064 & -0.0286 & -0.0046 & 0.0100 \\
0.8167 & -0.0277 & -0.0039 & -0.0044 & 0.0108 \\
0.8391 & 0.0149 & 0.0119 & -0.0039 & 0.0103 \\
\hline
\end{tabular}

Table 8: 4-level wavelet decomposition of $V_{7}$. 


\begin{tabular}{c|c|c|c|c}
$A_{4}$ & $D_{1}$ & $D_{2}$ & $D_{3}$ & $D_{4}$ \\
\hline 73.0235 & -0.0135 & -0.0375 & 0.0975 & -0.3610 \\
73.0854 & 0.0146 & 0.0010 & 0.0649 & -0.3520 \\
73.1909 & -0.0009 & 0.0442 & 0.0323 & -0.3217 \\
73.2898 & -0.0098 & 0.0527 & -0.0116 & -0.2692 \\
73.3579 & 0.0121 & 0.0091 & -0.0639 & -0.2016 \\
73.4667 & -0.0067 & -0.0234 & -0.0914 & -0.1395 \\
73.6397 & 0.0003 & -0.0189 & -0.0813 & -0.0951 \\
73.8266 & 0.0034 & -0.0166 & -0.0399 & -0.0710 \\
74.0156 & -0.0056 & -0.0171 & 0.0210 & -0.0656 \\
74.2021 & -0.0021 & -0.0032 & 0.0628 & -0.0616 \\
74.3624 & 0.0176 & 0.0149 & 0.0602 & -0.0472 \\
74.4935 & -0.0135 & 0.0268 & 0.0330 & -0.0300 \\
74.5991 & -0.0091 & 0.0261 & -0.0029 & -0.0118 \\
74.6850 & 0.0050 & -0.0000 & -0.0278 & 0.0092 \\
74.7759 & 0.0241 & -0.0399 & -0.0223 & 0.0306 \\
74.9135 & -0.0135 & -0.0373 & -0.0056 & 0.0578 \\
75.0896 & -0.0296 & 0.0159 & 0.0072 & 0.0908 \\
75.2003 & 0.0197 & 0.0346 & 0.0133 & 0.1159 \\
\hline
\end{tabular}

Table 9: 4-level wavelet decomposition of $V_{8}$.

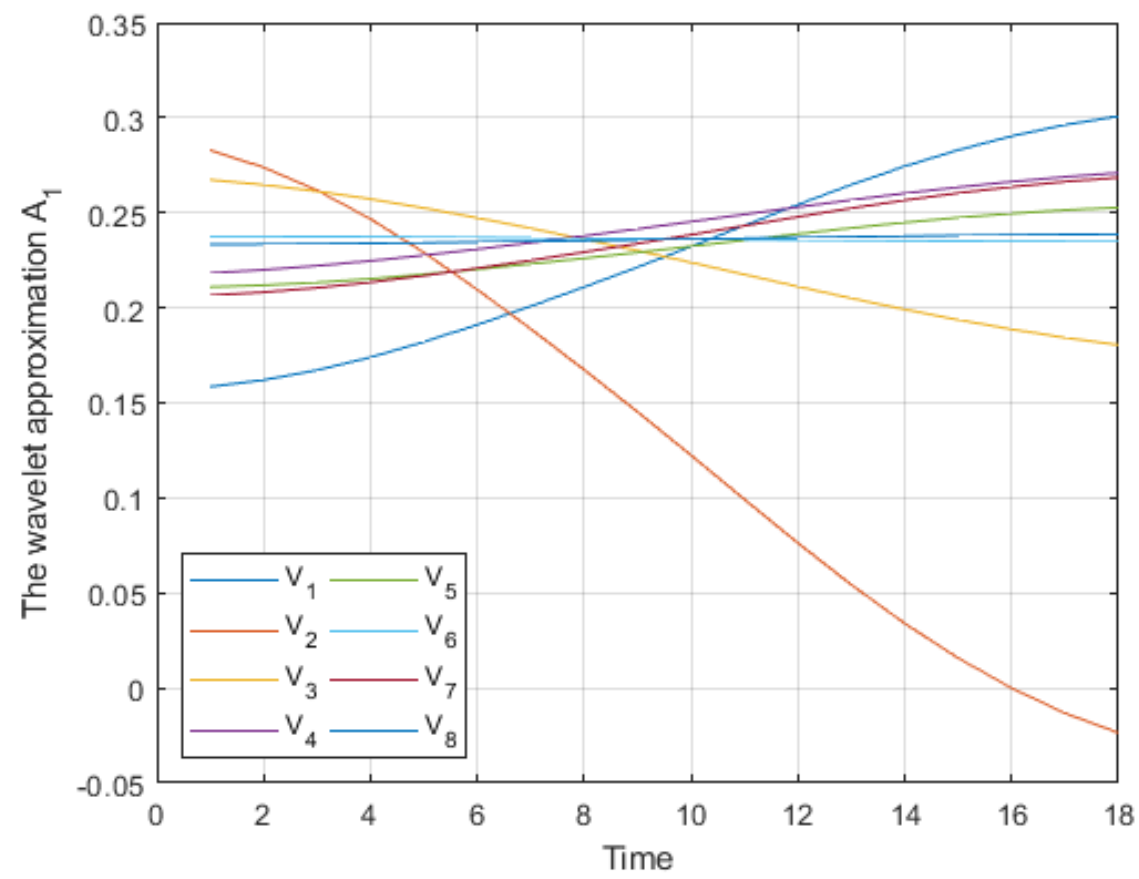

Figure 2. The 1-level wavelet approximation $A_{1}$ for variables $V_{i}, 1 \leq i \leq 8$. 


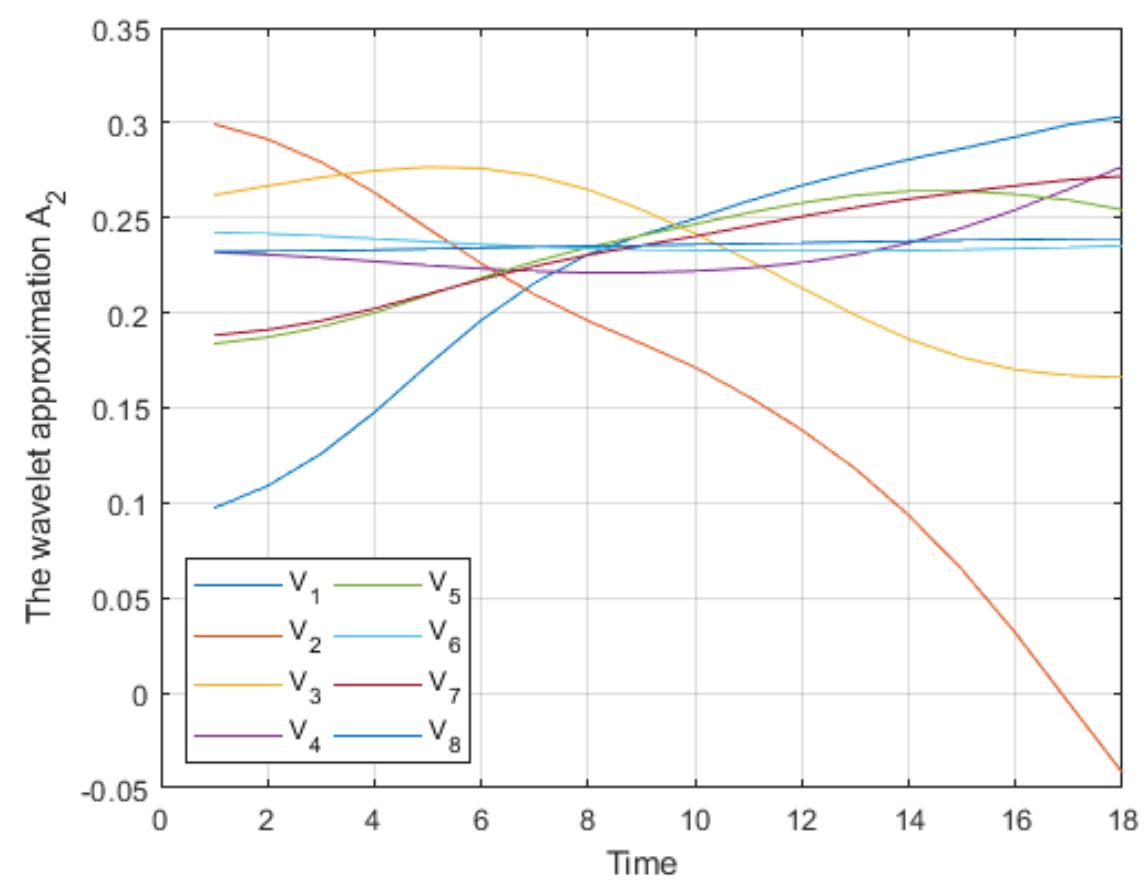

Figure 3. The 2-level wavelet approximation $A_{2}$ for variables $V_{i}, 1 \leq i \leq 8$.

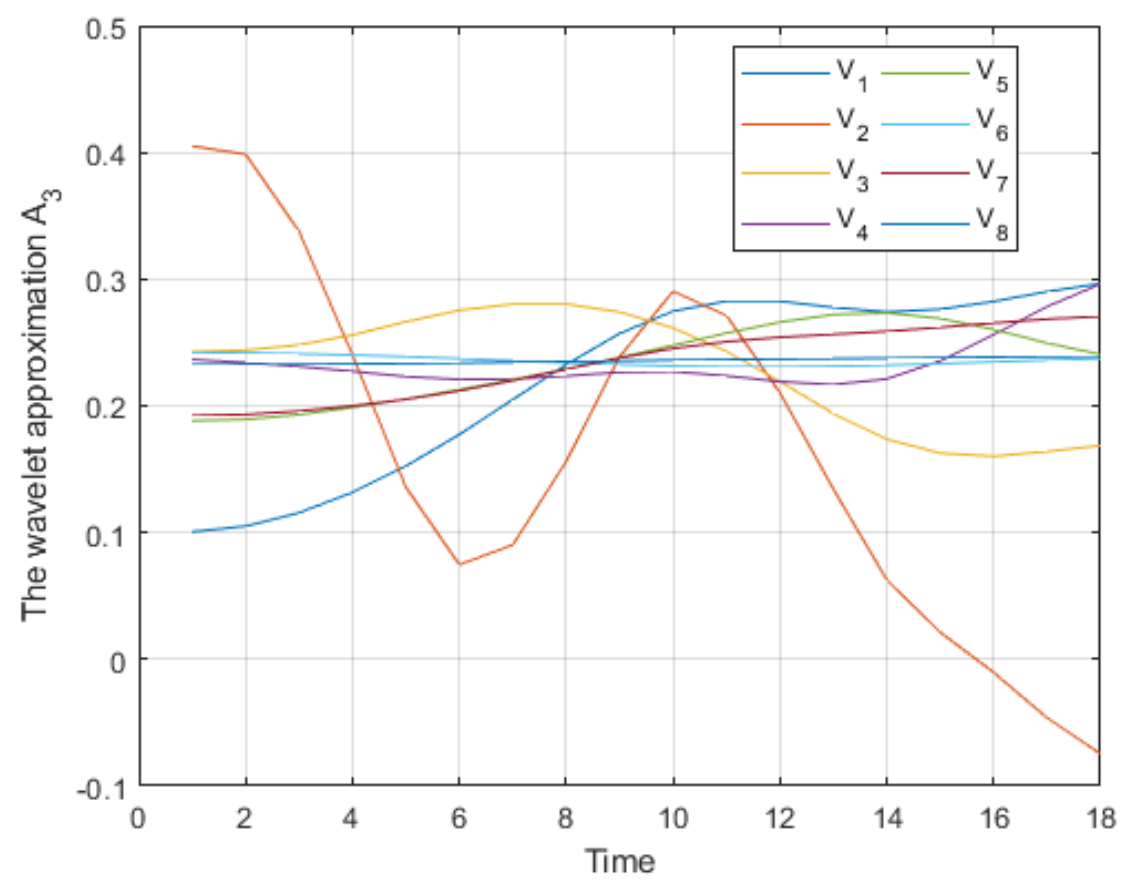

Figure 4. The 3-level wavelet approximation $A_{3}$ for variables $V_{i}, 1 \leq i \leq 8$. 


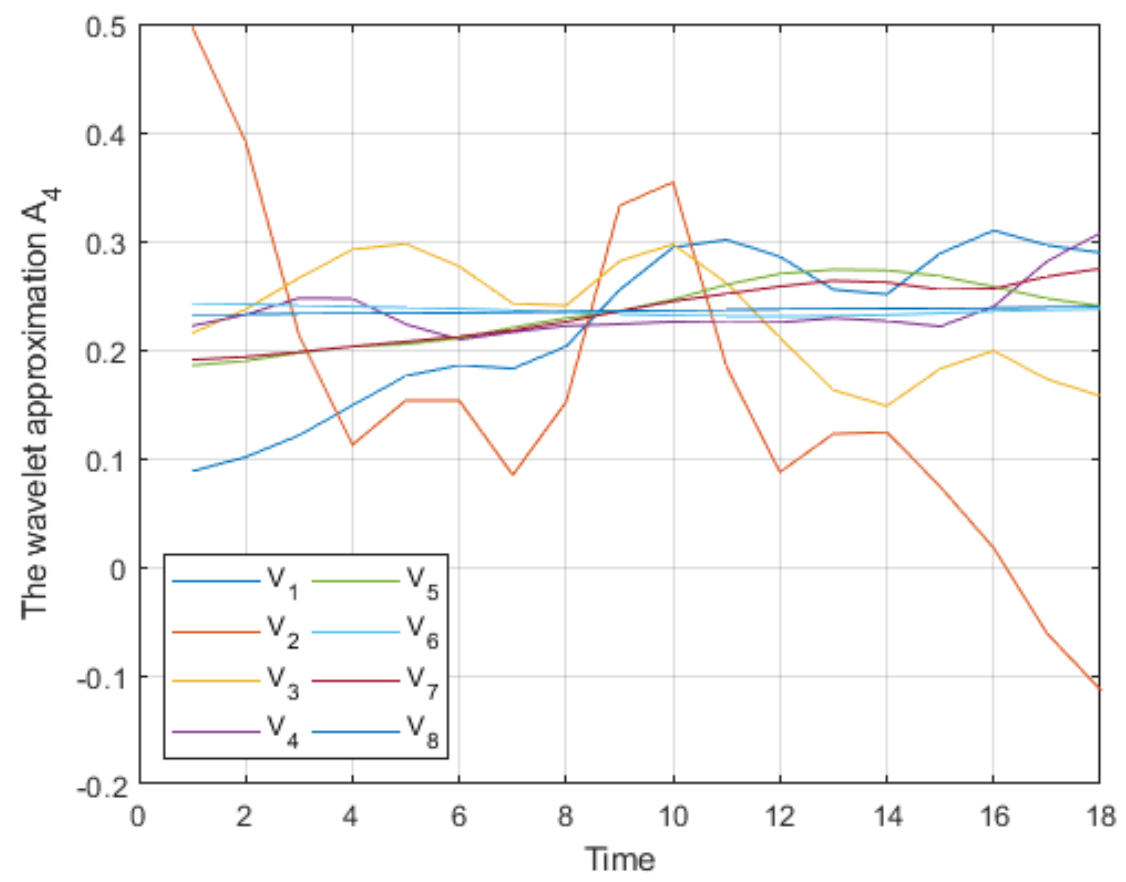

Figure 5. The 4-level wavelet approximation $A_{4}$ for variables $V_{i}, 1 \leq i \leq 8$.

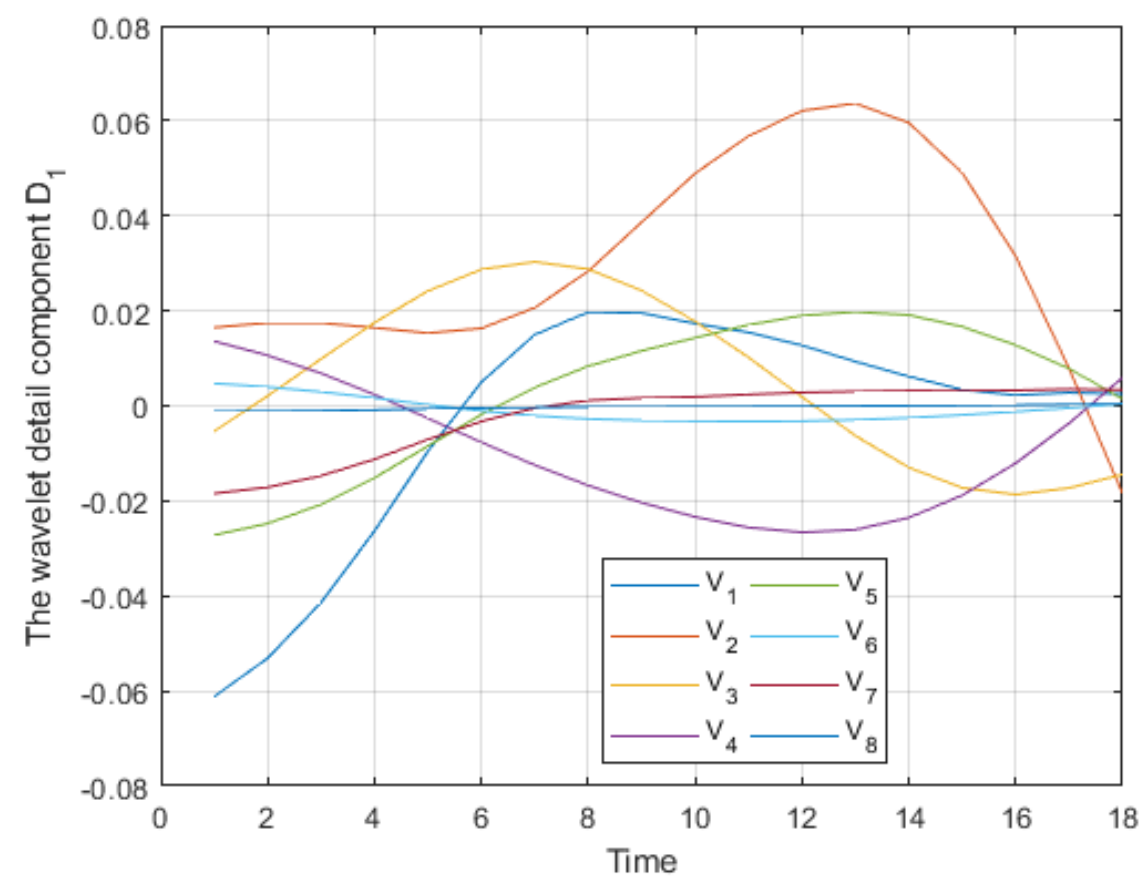

Figure 6. The 4-level wavelet detail component $D_{1}$ for variables $V_{i}, 1 \leq i \leq 8$. 


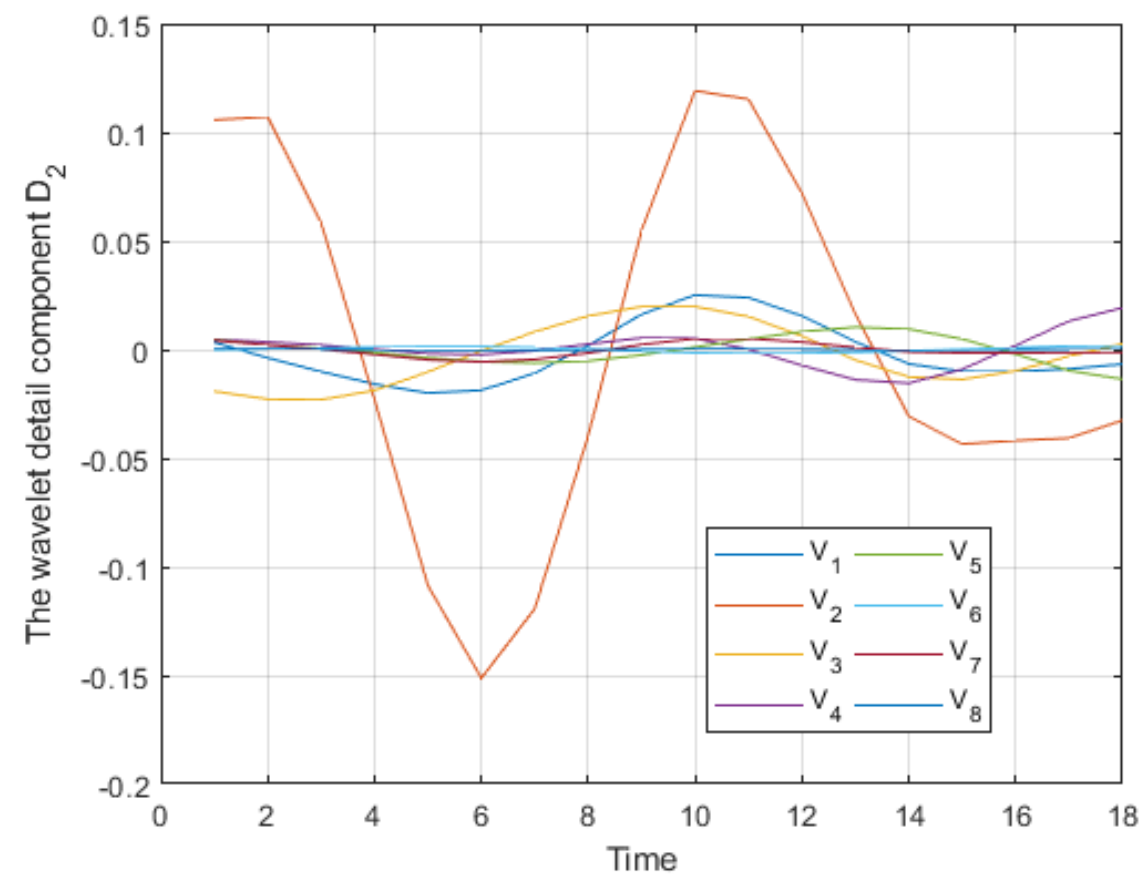

Figure 7. The 2-level wavelet detail component $D_{2}$ for variables $V_{i}, 1 \leq i \leq 8$.

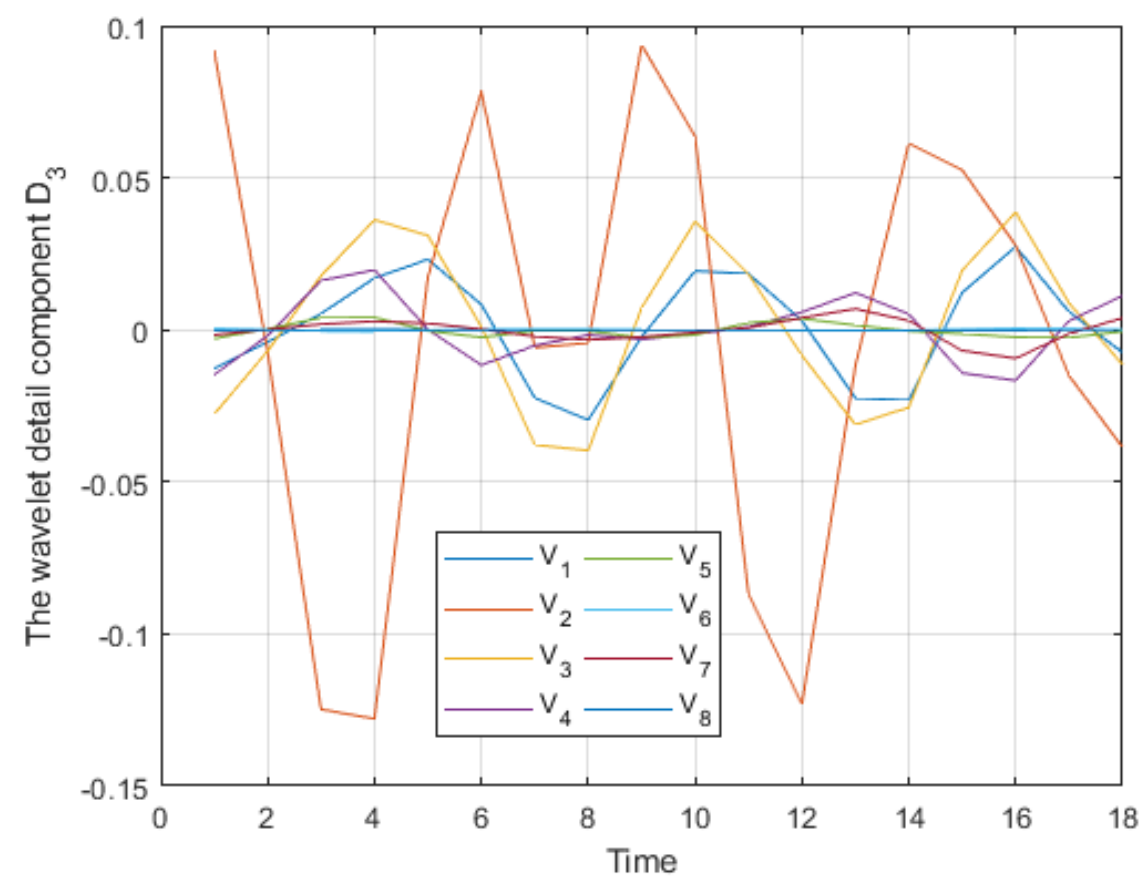

Figure 8. The 3-level wavelet detail component $D_{3}$ for variables $V_{i}, 1 \leq i \leq 8$. 


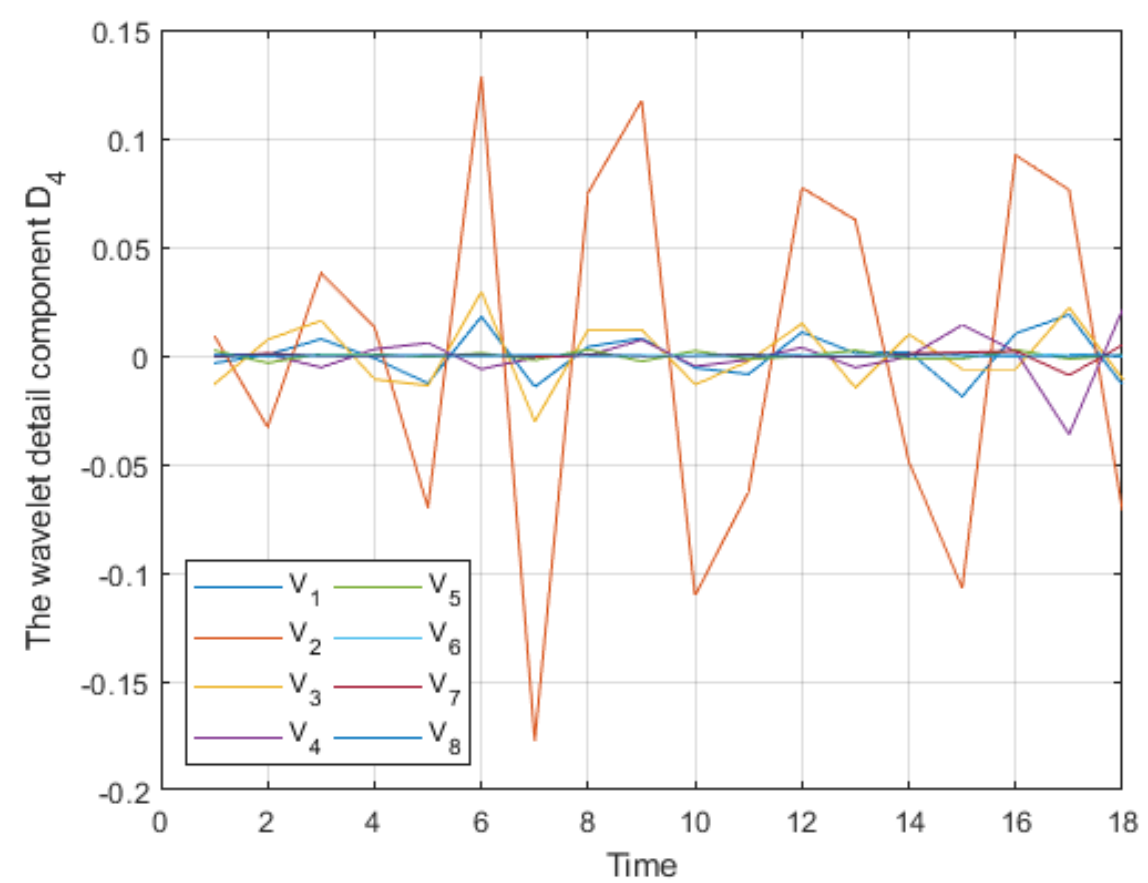

Figure 9. The 4-level wavelet detail component $D_{4}$ for variables $V_{i}, 1 \leq i \leq 8$.
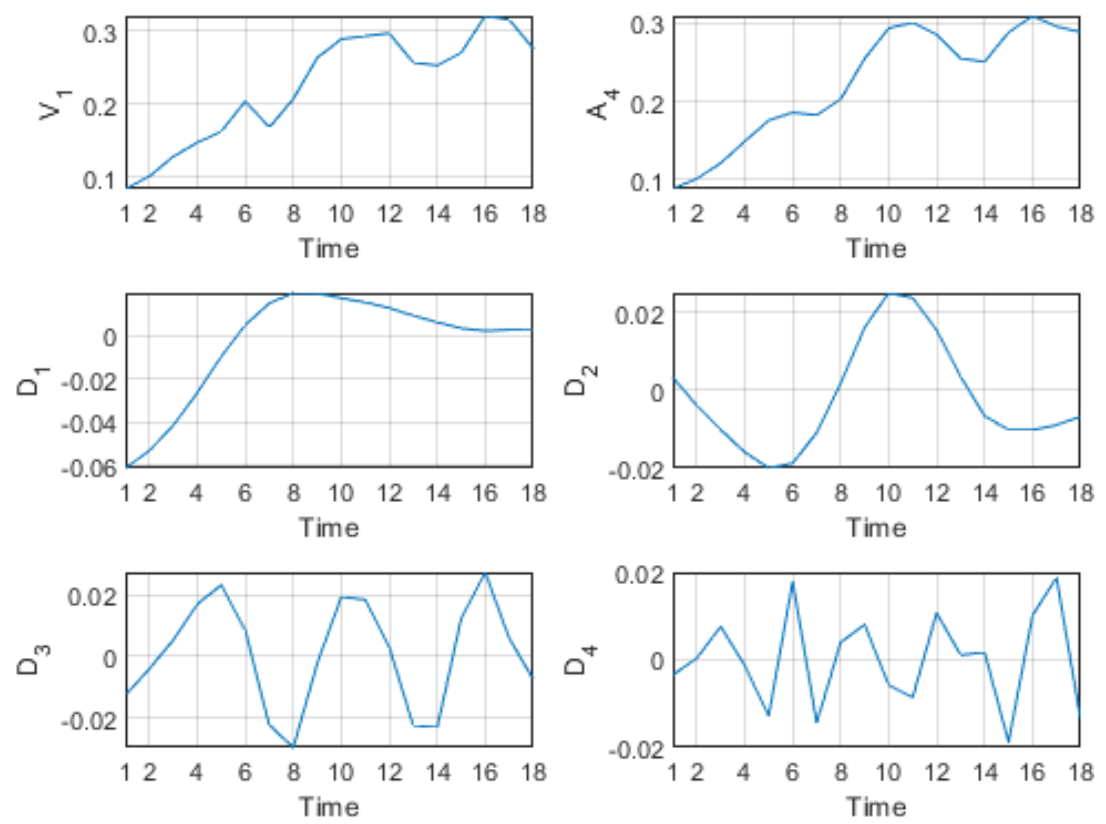

Figure 10. The 4-level wavelet decomposition of the variable $V_{1}$. 

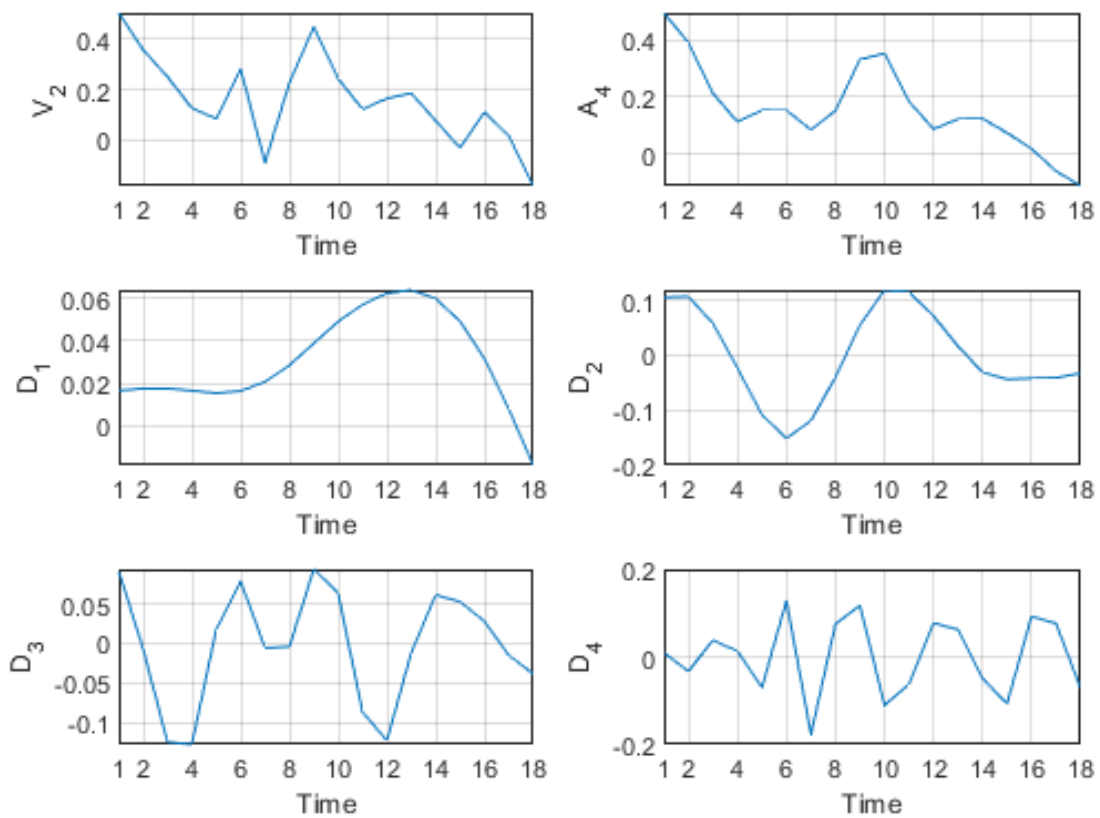

Figure 11. The 4-level wavelet decomposition of the variable $V_{2}$.
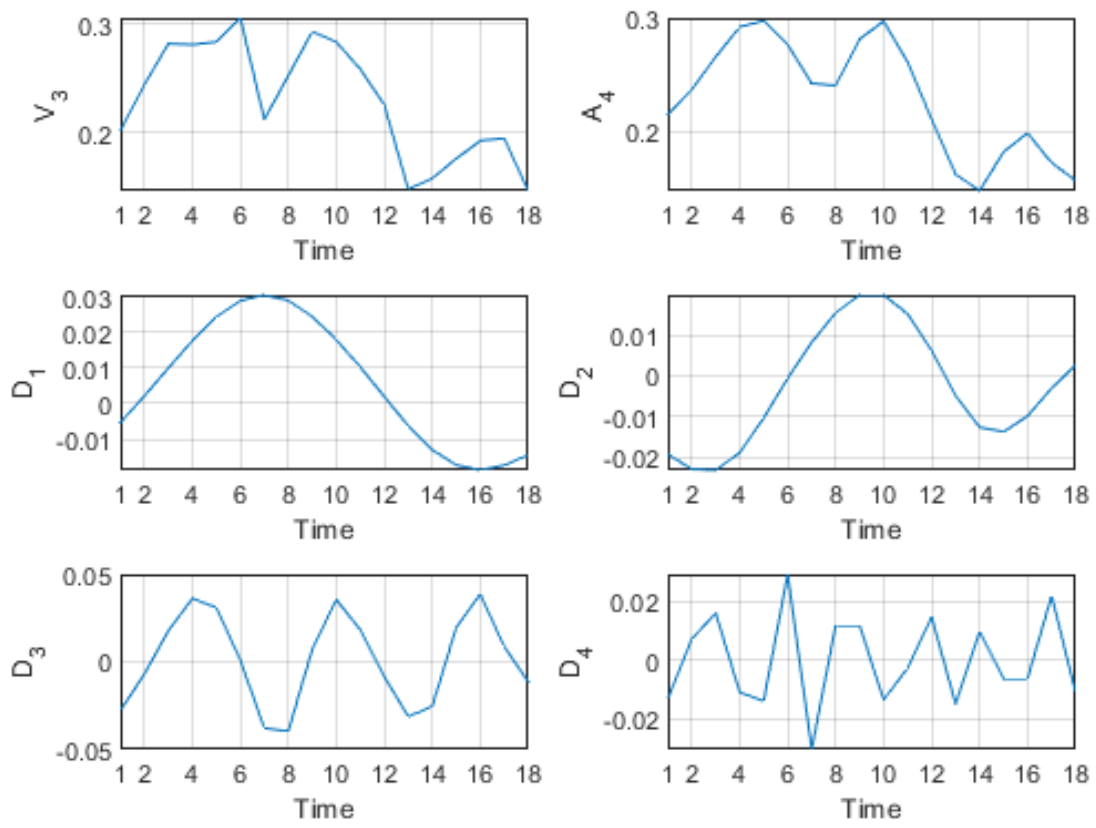

Figure 12. The 4-level wavelet decomposition of the variable $V_{3}$. 

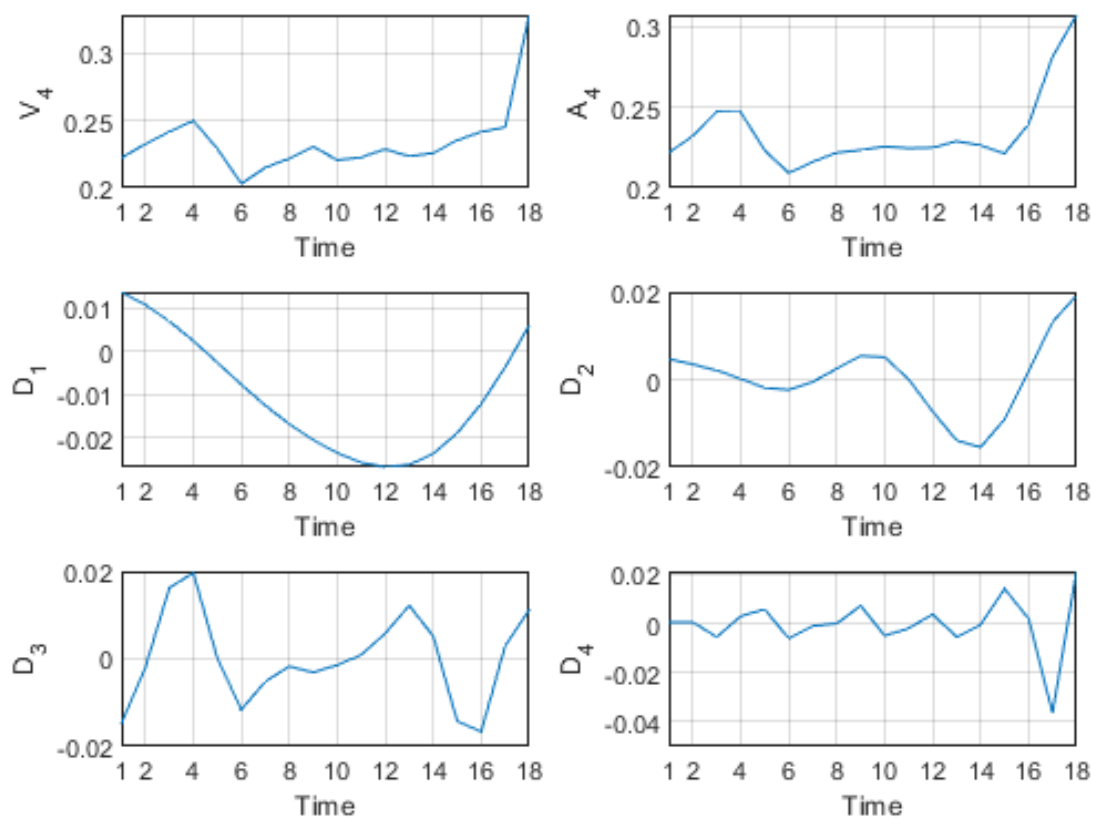

Figure 13. The 4-level wavelet decomposition of the variable $V_{4}$.
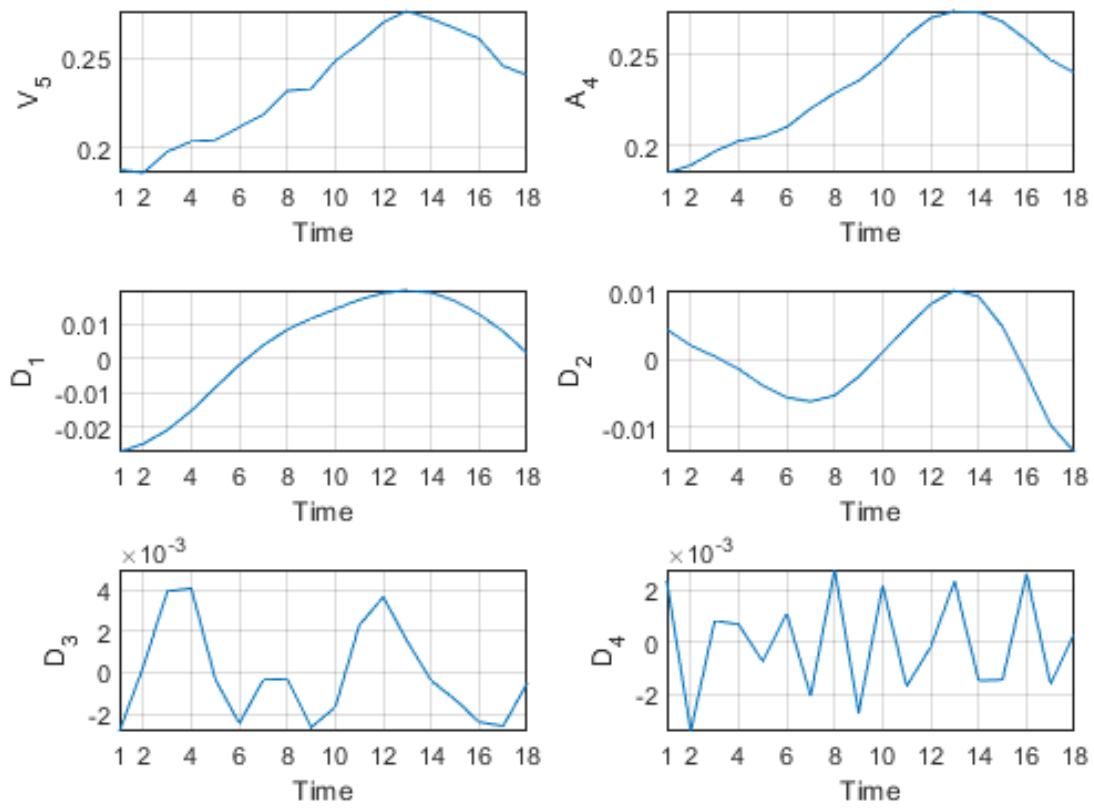

Figure 14. The 4-level wavelet decomposition of the variable $V_{5}$. 

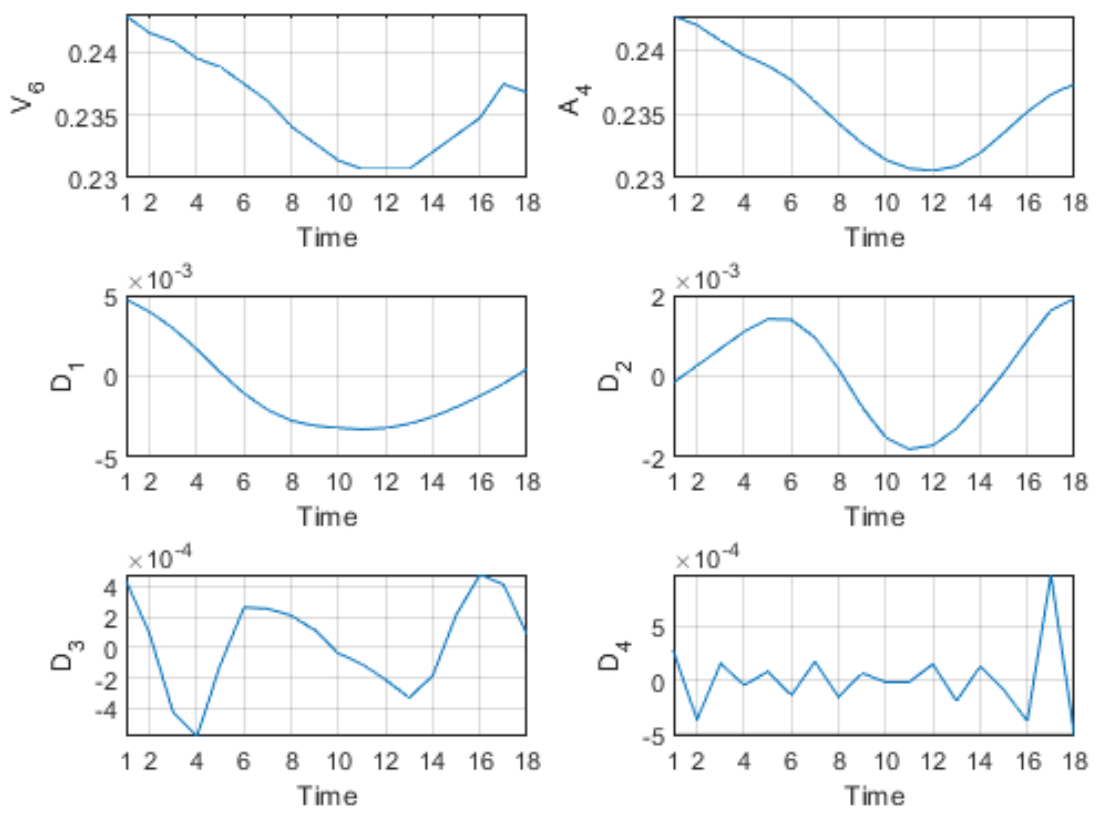

Figure 15. The 4-level wavelet decomposition of the variable $V_{6}$.
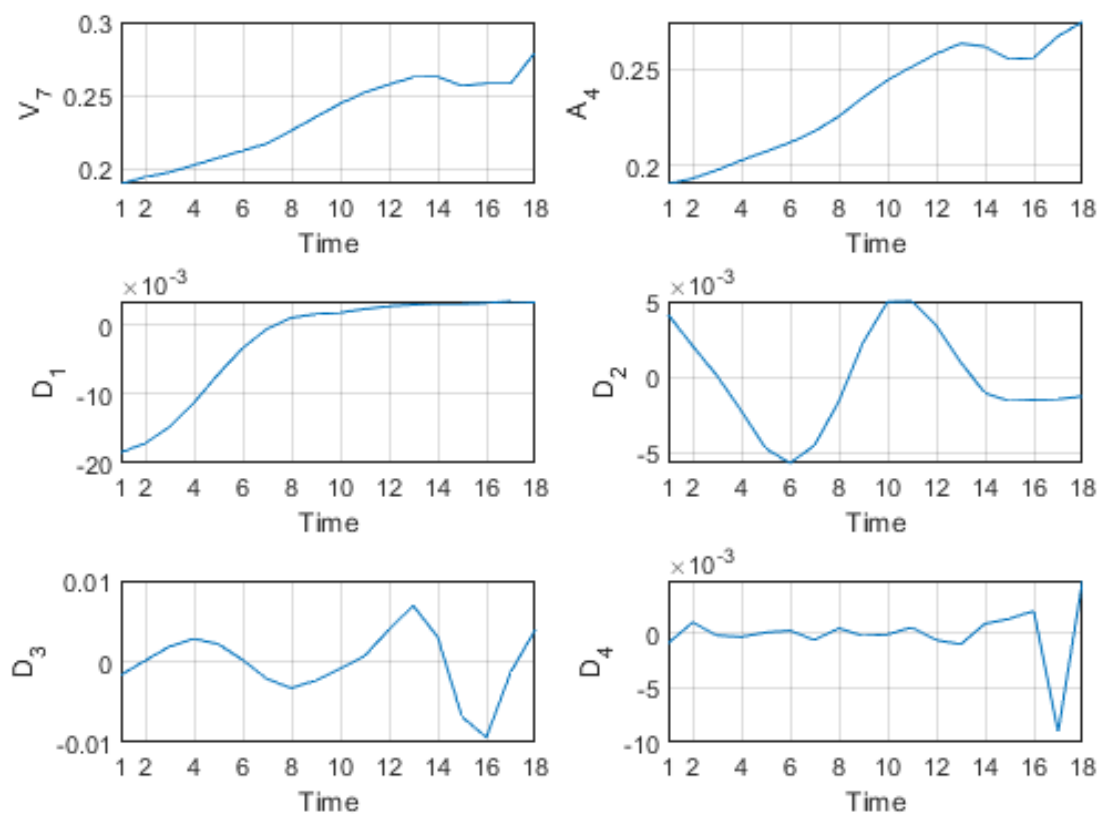

Figure 16. The 4-level wavelet decomposition of the variable $V_{7}$. 

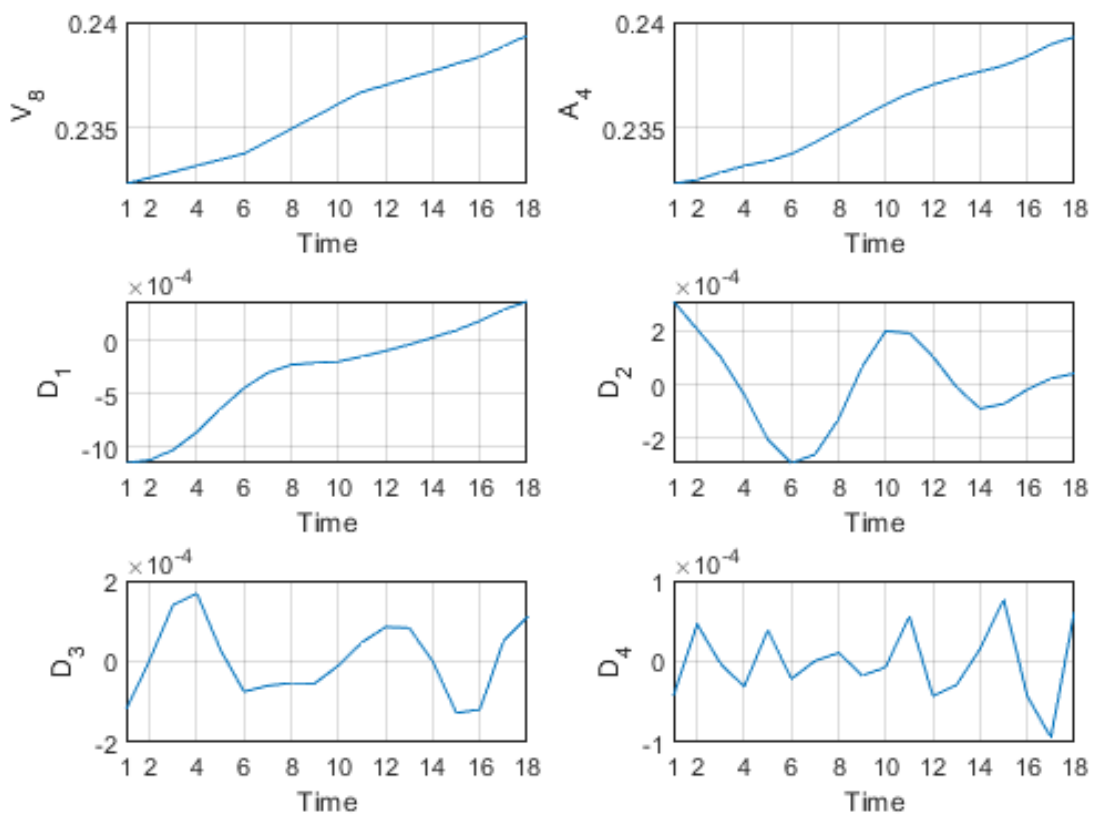

Figure 17. The 4-level wavelet decomposition of the variable $V_{8}$.

behavior starts to appear, explaining some pseudo-periodicity, and/or a fluctuation in the variation of the factor $V_{1}$. By means of quality of life vocabulary, this means that the situation is not stable, and thus the future quality of life situation should be carefully linked to the Gross Domestic Product. This later is unstable according to the time scale. Related to the case study, especially the period chosen, this is a natural consequence of many critical phenomena appeared in this period. The first is the starting steps in implementing the 2030-vision plans. As usual, with the absence of a real future view, and precise forecasting, and prevision of this plan, the statistics as well as the real behavior of investors, and citizens is always careful. The COVId-19 pandemic has been also dispersed in all the word, leading to a perturbation, sometimes a permanent stop of many important activities such as oil exportation, foreign investments, ..., etc. These facts affect the local or the national market, especially local or domestic production. For example by increasing prices of consummations, taxes, ... etc, which negatively affect the view of people regarding their lives, especially economic situation.

The variable $V_{2}$ representing the Gross National Income is going more to a decreasing shape, with more stability at medium horizons. As the time scale increases, this income shows more instability with always a decreasing magnitude. This may be due as evoked previously to many causes, especially the COVId-19, as well as the low movement of exportation. Recall also that the embargo against Qatar country where a big amount of especially food industry products is exported has been stopped for a long time relative estimated by the level $j=3$. Another cause is the restoring legitimacy war in Yemen, which has affected strongly and widely on the GCC continent in general. This phenomena has leaded to a big piece of money to be directed or exploited and reserved to the army activities and needs, more than the use in the investments that bring more interests to the treasury.

The variable $V_{3}$ relative to Gross Savings is some how increasing in low horizons, with a small perturbation in medium levels, and more instabilities at higher horizons. This behavior may be explained by the fact that the present or precisely the index is high at the beginning of the period, and starts to be unstable decreasing as the time scale increases. A main cause is firstly the increase in prices mainly of consumed products, the COVID-19 which stopped many, even small, activities. The increase of taxes as well 
as fuel prices, and cars. An important movement of immigration of citizens and thus an outside flow of money investments has taken place.

The employment rate denoted here by $V_{4}$ presents according to Figure 13 is somehow being stable, quietly constant with little variation from the its overage especially at short horizons. At the end of the period there is an extreme increase or what we call jump which may be explained by the movement of nationalization of jobs in the Kingdom, as part of the politics of the government already in the application and/or the execution of the 2030-vision plan to reduce the national unemployment rate. We know that Saudi Arabia, as well as the whole continent of GCC countries are relied in a large percentage on foreign incoming labor from abroad. GCC countries have planned some 2030 to 2035 vision plans, which target among many goals to reduce the non-national labor. However, in the last period, many crises have been appeared such as the COVID-19 as well as the Yemen war which affected severely the economy. Many industrial, as well as small firms have been closed due to the crisis. This explains well the increase of the unemployment rate suddenly. However, we stress on the fact that this instability is not really very big to affect strongly the variation of the unemployment rate. Besides, it is worthy to recall that Saudi nationals are not widely attracting the private sector, as they are in one side seeking high salaries, and on the other side they have more employment protections than expatriate workers, The government has made some policy to encourage the private sector for Saudi nationals recruitment such as the Nitaqat which deserves some prices to private firms that recruit Saudi nationals. This policy has effectively increased the employment rate in some short time horizons. However, with the non strong qualifications of this national labor, the private sector has known many perturbations by changing these workers by expatriates, which caused in turn many problems.

The variable $V_{5}$ designates the Energy Consumption per Capita. Concerning this index, Saudi Arabia is one of the most important country and force that may provide completely all the population with self-produced energy. Moreover, it may produce an over self-produced energy, which is by the next and in the majority exported. This makes the index of Energy consumption globally increasing in short horizons as it is shown in Figure 14. This may be naturally explained by the availability of energy to be delivered to the population time-wise. However, at long horizons, we notice some perturbation shown clearly in the detail component $D_{4}$ relative to this factor. This explains the influence of the global crisis due to COVID-19, the Yemen war which has led to a lack in technology importation as a main cause. See also [30]. We may also here relate this perturbation to the act of nationalization of jobs when including non qualified. Besides, one of the main plans in the 2030-vision is the NEOM city that the kingdom started to implement in the Northwest region. This project has a great influence as a great part of energy as well as huge amount of money is now conserved to succeed such a project. In other words, a type of austerity policy is carried out in order to save both energy, and money for the NEOM project.

Figure 15 illustrates the behavior of the variable $V_{6}$ due to the Death Rate in the kingdom. It shows a decreasing rate due to the development taking place in the health sector, in particular, and services sector to the population in all over the country. It is also worth noting the infrastructure development, which contributed to reducing transport accidents. These factors explain well the decreasing behavior at short to medium horizons, unless some perturbation at higher levels, where a jump to the top in the Death Rate has been illustrated in the last period, which is mainly due to the COVID-19 victims. This factor is strongly linked to the Life Expectancy explained by the variable $V_{8}$. Figure 17 shows a globally and strictly increasing behavior especially in short horizons. The governmental statistics estimated that effectively the Life Expectancy increased from approximately 70 years at 2003 to reach 75.5 at the present. This is clearly illustrated by the variable $V_{8}$. At long or higher time scales, we notice some fluctuations even weak around the mean value, which may be explained effectively by the previous 
variable where the death rate has somehow increased due to the COVID-19 pandemic. Recall that such a pandemic affects and still affect aged persons whom age crossed the forty years old.

The last index or factor is due to the Education index designated here by the variable $V_{7}$. This factor or index is the most important one in the Saudi Arabia plans for many years ago, as well as in its 2030-vision projects. Indeed, for many years ago, the authorities in the kingdom has made the education and its improvement and development as a primary goal. Serious revisions of programs starting from the early primary school, secondary as well as higher education have been carried on. Moreover, since the past decade, the state has begun to establish educational institutions throughout the Kingdom, including higher education, as universities have been established in every governorate center. As for the areas that are relatively far from the governorate centers, colleges have been established under the name of university colleges, which is a kind of university institution that gathers under its umbrella many literary, scientific, social and human sciences disciplines at the same time. Within some flexible laws, the Ministry of Higher Education enables the transfer, integration, and mutation of students between these university colleges and other independent colleges, which enables the students to continue their studies smoothly.

The state has also allocated large amounts of money to reform education and infrastructure, upgrade scholarships, and establish a scholarship system abroad within the framework of master's and doctoral degrees and language studies. The scholarship system has made it possible to significantly improve the level of teachers and to develop scientific research in national universities and the administrative system as well.

Besides, the kingdom has already a platform allowing its universities to collaborate with all the world, especially Arab countries, by recruiting qualified staff members. This mixture of different educational systems, and cultures allowed the education level to be improved well.

These facts are clearly reflected by the variable $V_{7}$ where an increasing behavior is clearly detected especially at short horizons, or low time scales. The last years, it has been although noticed some little decrease in this index due to many reasons. One of the reasons may be explained by the state's austerity policy followed by the state on all governmental and national private institutions within the framework of the policy of guiding consumption and preserving public money. It should also be noted that spending on other issues such as defense and/or army in the face of the Yemen war and Iranian expansion may have effects on reducing local internal budgets to provide them to the Defense. Among the important projects, we also mention the NEOM Global Village project, which began to be established, where the Ministry of Education in general linked all its projects and outputs to the goals and projects of NEOM plans within the framework of 2030-Vision. This has made a large part of the educational institutions' allocations fall under a joint administration with NEOM. See Table 7 and Figure 16.

Next, as the components of our sample are illustrated, described, analyzed and interpreted, we provide the resulting Quality of Life index HDI issued from the model ( 21). The values are provided in Table 10 below.

Figure 18 illustrates graphically the behavior of the quality of Life index HDI, and provides thus a graphical comparison between the real values, and the one due to our wavelet multi-scale model (21).

Notice from Table 10 and Figure 18 that the wavelet multi-scale model succeeded to reflect or to localize the real behavior of the HDI relatively to time scales. Contrarily to existing methods which yield a global value on each a priory fixed period independently to other, and to the scale, we here notice that the HDI may posses a different time scale behaviors. Related to the case of study, the HDI is increasing at short to medium horizons reflecting a good well-being and/or a satisfaction versus the quality of life in the Kingdom especially at the beginning of the period of study. 


\begin{tabular}{c|c|c|c|c}
$H D I_{0}$ & $H D I_{1}$ & $H D I_{2}$ & $H D I_{3}$ & $H D I_{4}$ \\
\hline 0.7841 & -0.0021 & -0.0033 & 0.0046 & -0.0284 \\
0.7859 & 0.0021 & 0.0001 & 0.0019 & -0.0260 \\
0.7886 & 0.0004 & 0.0033 & -0.0003 & -0.0220 \\
0.7920 & -0.0007 & 0.0048 & -0.0028 & -0.0164 \\
0.7962 & -0.0010 & 0.0030 & -0.0055 & -0.0096 \\
0.8008 & 0.0019 & -0.0007 & -0.0067 & -0.0033 \\
0.8057 & -0.0016 & -0.0039 & -0.0059 & 0.0017 \\
0.8108 & 0.0007 & -0.0044 & -0.0032 & 0.0050 \\
0.8161 & 0.0002 & -0.0012 & 0.0011 & 0.0068 \\
0.8216 & -0.0007 & 0.0013 & 0.0047 & 0.0080 \\
0.8273 & 0.0004 & 0.0014 & 0.0063 & 0.0095 \\
0.8329 & -0.0004 & 0.0024 & 0.0065 & 0.0106 \\
0.8383 & 0.0007 & 0.0037 & 0.0054 & 0.0110 \\
0.8432 & 0.0004 & 0.0014 & 0.0033 & 0.0107 \\
0.8477 & -0.0024 & -0.0036 & 0.0008 & 0.0096 \\
0.8515 & 0.0020 & -0.0052 & -0.0023 & 0.0081 \\
0.8547 & 0.0005 & -0.0018 & -0.0056 & 0.0062 \\
0.8572 & -0.0008 & 0.0013 & -0.0071 & 0.0034 \\
\hline
\end{tabular}

Table 10: The HDI index, real and time scale model (21).
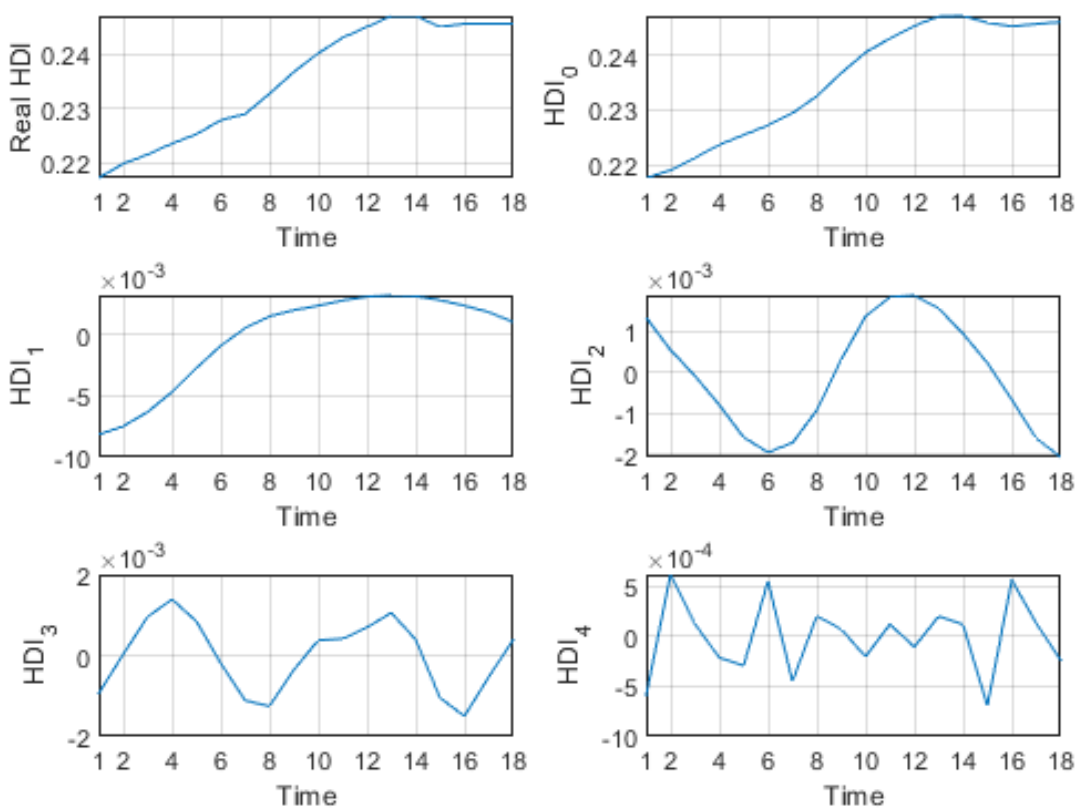

Figure 18. Graph of the HDI index, real and time scale model (21). 
Overall, the present study concludes clearly and strongly that time-scale decomposition is very important for analyzing quality of life index as well as its factors. In particular, we conclude easily that the case study of Saudi Arabia during the period 2003-2020 is an appropriate period to model the quality of life index is at the time scale, which is clearly dominated by a trend. At higher scales (i.e., low frequencies), the wavelet details permit to localize the instabilities in the index behavior,and thus allows the researchers to analyze the eventual causes. In low horizons, the fit is generally well.

Existing models dealing with the quality of life are in the majority independently based on health situation, or economic one. So, only the influence of the health situation of individuals or the influence of the economical variables are estimated in these models. However, there may be many dimensions and factors that influence the population life and their satisfaction such as education, security, employment, ..., etc.The present model,even it has not considered all the facts related to quality of life, tried to include many of them to estimate a more adequate index.

\section{Conclusion}

The present paper concerns the estimation of a quality of life index by using wavelet theory as a mathematical tool to discover the influence of the time scale on such an index. A wavelet multi scale then provided allowing the estimation of the quality of life index in Saudi Arabia.

The present work confirms the idea stating that generally to estimate a quality of life or population satisfaction and well-being, it is necessary to define the areas where the individuals can realise their possibilities at different levels, such us the availability of services, health care, education, security and safety (economic and physical), dignity, communication, participation in decision-making, etc.

The present model may be improved to include more dimensions such as material living standards, political voice and governance, social connections and relationships, environment, etc. We join here the models discussed theoretically in $[26,27]$. We think that a hybrid idea may lead to better estimates and understanding of the quality of life index. A future eventual extension of the present study may be also the consideration of factor analysis as a classical tool especially in social sciences.

\section{Author Contributions:}

Conceptualization, M. S. Balalaa and A. Ben Mabrouk; Methodology, M. S. Balalaa and A. Ben Mabrouk; Software, M. S. Balalaa and A. Ben Mabrouk; Validation, M. S. Balalaa and A. Ben Mabrouk; Formal analysis, M. S. Balalaa and A. Ben Mabrouk; Investigation, M. S. Balalaa and A. Ben Mabrouk; Resources, M. S. Balalaa and A. Ben Mabrouk; Data curation, M. S. Balalaa and A. Ben Mabrouk; Writing-original draft preparation, M. S. Balalaa and A. Ben Mabrouk; Writing-review and editing, M. S. Balalaa and A. Ben Mabrouk; Visualization, M. S. Balalaa and A. Ben Mabrouk; Supervision, M. S. Balalaa and A. Ben Mabrouk; Project administration, M. S. Balalaa and A. Ben Mabrouk; Funding acquisition, M. S. Balalaa and A. Ben Mabrouk. All authors have read and agreed to the published version of the manuscript.

\section{Funding:}

This research received no external funding.

\section{Acknowledgments:}

\section{Conflicts of Interest:}

The authors declare no conflict of interest. 
1. Alves H., Vázquez J.L., Quality-of-Life Marketing: An Introduction to the Topic. In: Alves H., Vázquez J. (eds) Best Practices in Marketing and their Impact on Quality of Life. Applying Quality of Life Research: (Best Practices). Springer, Dordrecht, 2013.

2. Arfaoui S, Rezgui I, Mabrouk AB (2017) Wavelet Analysis On The Sphere, Spheroidal Wavelets, Degryuter, Degruyter, 2017, ISBN 978-3-11-048188-4.

3. Arfaoui S, Ben Mabrouk A and Cattani C (2021) Wavelet analysis Basic concepts and applications, CRC Taylor-Francis, Chapmann \& Hall, Boca Raton, 1st Ed., April 21, 2021.

4. Arndt J., Marketing and the quality of life. Journal of Economic Psychology, 1(4) (1981), pp. 283-301.

5. Ben Mabrouk A, Kahloul I and Hallara S.-E (2010) Wavelet-Based Prediction for Governance, Diversification and Value Creation Variables. International Research Journal of Finance and Economics, 60 (2010), 15-28.

6. Boscaiu, V., and Voda, V. G. (2008). Aplicatii ale seriilor de timp vectoriale in controlul calitatii, Applications of the vector time series in quality control. Revista Calitate si Management, 7, $42-45$.

7. A. Bucur (2017) How can we apply the models of the quality of life and the quality of life management in an economy based on knowledge?, Economic Research Ekonomska Istrazivanja, 30(1), 629-646.

8. Bucur, A. (2013). Modeling as a multiple-criteria decision-making problem and simulation, for the hierarchization of programs of study. Proceedings of the Advances in Automatic Control Modelling and Simulation, Braşov, 338-343.

9. Bucur, A. (2014a). An indicator of an individual's professional quality. Proceedings of the 8th International Conference on Applied Mathematics, Simulation, Modelling, Florence, 342-345.

10. Bucur, A., and Oprean, C. (2014). Operational research and applications in quality management. Saarbrücken: LAP Lambert Academic Publishing.

11. Caescu S. C., Constantinescu M. and Ploesteanu M. G., Strategic Marketing And Quality Of Life, Annals of Faculty of Economics, University of Oradea, Faculty of Economics, 1(2) (2012), pp. 801-806.

12. Cella, D. F., \& Cherin, E. A. (1987). Measuring quality of life in patients with cancer. In Proceedings of the American Cancer Society fifth national conference on human values and cancer (pp. 23-31). Atlanta, GA.

13. Colby, B. N. (1987). Well-Being: A Theoretical Program. American Anthropologist, 89, 879-895.

14. M. Constantinescu, The Relationship between the Quality of Life Concept and Social Marketing Development. International Journal of Economic Practices and Theories, 2(2) (2012), pp. 75-80.

15. Costanza, R., Fisher, B., Ali, S., Beer, C., Bond, L., Boumans, R., Snapp, R. (2008). An integrative approach to quality of life measurement, research, and policy. S.A.P.I.EN.S, 1, $16-21$.

16. Daubechies, I. (1992) Ten Lectures on Wavelets- Society for Industrial and Applied Mathematics. Philadelphia.

17. P. M. Fayers, and D. Machin, Quality of Life The assessment, analysis and interpretation of patient-reported outcomes. Second edition, 2007 John Wiley \& Sons, Ltd. West Sussex PO19 8SQ, England.

18. M. N. Hajli, A study of the impact of social media on consumers. International Journal of Market Research 56(3) (2014), pp. 387-404.

19. Hubbard BB (1998) The world according to wavelets: The story of a mathematical technique in the making, 2e, Ak Peters Ltd., MA.

20. N. Jones, R. Borgman and E. Ulusoy, Impact of social media on small Businesses. Journal of Small Business and Enterprise Development 22(4) (2015), pp. 611-632

21. Lee D.-J., and Sirgy M. J., Quality-of-Life (QOL) Marketing: Proposed Antecedents and Consequences. Journal of Macromarketing, 24(1) (2004), pp. 44-58.

22. Mallat S. (2008) A Wavelet Tour of Signal Processing. Academic Press, 3rd ed. Dec. 2008.

23. McCall, S. (1975). Quality of life. Social Indicators Research, 2, 229-248.

24. Michalos, A. C. (Ed.). (2014). Encyclopedia of quality of life and well-being research. Netherlands: Springer. 
25. Oprean, C., \& Bucur, A. (2013). Modeling and simulation of the quality's entropy. Quality \& Quantity, 47, 3403-3409.

26. Puskorius, S., Theoretical Model of Estimating the Quality of Life Index. Intellectual Economics 8 (1)(19) (2014), pp. 55-64.

27. Puskorius, S., The Methodology of Calculation the Quality of Life Index. International Journal of Information and Education Technology, 5(2) (2015), pp. 156-159.

28. Sarraj, M., and Ben Mabrouk, A., The Systematic Risk at the Crisis - A Multifractal NonUniform Wavelet Systematic Risk Estimation. Fractal Fract. 2021, 5(4), 135.

29. Schuessler, K. F., \& Fisher, G. A. (1985). Quality of life research and sociology. Annual Review of Sociology, 11, 129-149.

30. Shaikh, I. (2021) On the relation between the crude oil market and pandemic Covid-19. European Journal of Management and Business Economics, Vol. 30 No. 3, 2021 pp. 331-356.

31. S. Siddiqui and T. Singh, Social Media its Impact with Positive and Negative Aspects, International Journal of Computer Applications Technology and Research, 5(2) (2016), pp. 71-75.

32. Sirgy, M. Joseph, et al. The Interface between Quality of Life and Marketing: A Theoretical Framework. Journal of Marketing \& Public Policy, 1 (1982), pp. 69-84.

33. M. Joseph Sirgy and A. Coskun Samli, New Dimensions in Marketing. Quality of Life Research.

34. Soltani S, (2002) On the use of the wavelet decomposition for time series prediction. Neurocomputing 48 (2002) 267-277.

35. Soltani, S, Modarres, R, and Eslamian, S. S., (2007) The use of time series modeling for the determination of rainfall climates of Iran. Int. J. Climatol. 27: 819-829.

36. Terhune, K. W. (1973). Probing policy relevant questions on the quality of life. In The quality of life concept. Washington: Environmental protection agency.

37. M. A., Testa, M.P.H., and Donald C. Simonson M.D, Assessment of quality of life outcomes. The new England Journal of Medicine 334(13) (1996), pp. 835-840.

38. Veenhoven, R. (2006). The four quality of life. ordering concepts and measures of the good life. In Mark McGillivray \& Mathew Clark (Eds.), Understanding human well-being (pp. 74-100). Tokyo-New York-Paris: United Nations University Press.

39. Wilczek B., Media use and life satisfaction. The moderating role of social events. International Review of Economics. Online first 19 January 2018, 49 pages. 
